Federal Reserve Bank of Minneapolis

Research Department Staff Report 433

August 2009

\title{
Methods versus Substance: Measuring the Effects of Technology Shocks on Hours*
}

\author{
Cristina Fuentes-Albero \\ University of Pennsylvania \\ Maxym Kryshko \\ University of Pennsylvania \\ José-Víctor Ríos-Rull \\ University of Minnesota, \\ Federal Reserve Bank of Minneapolis, \\ CAERP, CEPR, and NBER \\ Raül Santaeulàlia-Llopis \\ Washington University in St. Louis \\ Frank Schorfheide \\ University of Pennsylvania, CEPR, and NBER
}

\begin{abstract}
In this paper, we employ both calibration and modern (Bayesian) estimation methods to assess the role of neutral and investment-specific technology shocks in generating fluctuations in hours. Using a neoclassical stochastic growth model, we show how answers are shaped by the identification strategies and not by the statistical approaches. The crucial parameter is the labor supply elasticity. Both a calibration procedure that uses modern assessments of the Frisch elasticity and the estimation procedures result in technology shocks accounting for $2 \%$ to $9 \%$ of the variation in hours worked in the data. We infer that we should be talking more about identification and less about the choice of particular quantitative approaches.
\end{abstract}

*J.-V. Ríos Rull: vr0j@umn.edu; F. Schorfheide, schorf@ssc.upenn.edu; C. Fuentes-Albero: fuentesa@econ. upenn.edu; M. Kryshko: mkryshko@sas.upenn.edu; R. Santaeulàlia-Llopis: rauls@wustl.edu. We thank seminar participants at the 2007 NASM, the 2007 San Sebastían Summer School, FRB Philadelphia, the 2007 CREI Conference on "How Much Structure in Macro Models," CEMFI, Cornell, NYU, USC, and the Wharton Macro Lunch, for helpful comments. Ríos-Rull thanks the National Science Foundation (Grant SES-0079504). Schorfheide gratefully acknowledges financial support from the Alfred P. Sloan Foundation and the National Science Foundation under Grant SES 0617803. The views expressed herein are those of the authors and not necessarily those of the Federal Reserve Bank of Minneapolis or the Federal Reserve System. 


\section{Introduction}

Over the past three decades, quantitative macroeconomics has witnessed controversies about the role of formal econometric methods. While there is some broad consensus that the neoclassical stochastic growth model — potentially augmented by heterogeneity, various types of frictions, and different sources of idiosyncratic as well as aggregate uncertainty provides a useful framework for substantive empirical work, there is less consensus on how such models should be parameterized in view of the available economic data and on how to document the precision and robustness of quantitative results. Following Kydland and Prescott (1982), many researchers calibrate dynamic stochastic general equilibrium (DSGE) models, whereas other researchers use formal econometric methods to parameterize DSGE models and study their quantitative implications.

Most of the methodological controversy can be attributed to an apparent trade-off between theoretical coherence and empirical fit of macroeconomic models and its implications for empirical research. In this paper, we make the case that it is not the choice of quantitative approach per se that is responsible for empirical findings, but rather the implicit identification of key parameters associated with the particular mappings from data into the parameter space. Thus, sources of identification and not a controversy over the use of formal statistical methods should be at the center of the debate in quantitative macroeconomics.

To build our case, we measure the contribution of both neutral and investment-specific technology shocks to movements in hours worked. We compare the answers obtained with the calibration and likelihood-based estimation of a neoclassical stochastic growth model. The key parameter in the analysis is the labor supply elasticity. If this elasticity is chosen according to the most recent household-level estimates, those that carefully account for movements in and out of the labor force as well as the joint behavior of two spouses, then productivity shocks are responsible for less than $10 \%$ of hours variation. For other values of the Frisch elasticity used in the calibration literature, the contribution of technology shocks ranges from less than $1 \%$ to almost $150 \%$. Our likelihood-based analysis, implemented with Bayesian techniques, ${ }^{1}$ also leads to the conclusion that technology shocks account for less than $10 \%$ of the variance of hours. Unlike previous papers, we carefully discuss the source of

\footnotetext{
${ }^{1}$ Our use of Bayesian techniques instead of a frequentist econometric approach is partly a personal choice, and partly a statement about the state of the art in DSGE model estimation. Differences between the two modes of statistical inference are the object of other research.
} 
labor supply elasticity identification and its potential sensitivity to model misspecification in a likelihood-based framework.

To make our empirical analysis as transparent as possible, we have deliberately chosen a fairly simple DSGE model, rather than a more sophisticated specification as in Justiniano, Primiceri, and Tambalotti (2009a). Our model allows us to focus on a single parameter, which is difficult to measure and at the same time crucial for the quantitative result. The difficulty in determining the labor supply elasticity is in part caused by the stylized nature of our theoretical model. While a more sophisticated DSGE model might remedy some of the misspecifications of a simpler model, it is natural to confront the larger model with a richer set of observations. Hence, the data will always have patterns that the enlarged model is unable to explain, and misspecification will be a concern. While our empirical analysis is concerned with a question of the form How much of $Y$ can be explained by $X$ ? our main point extends to other questions, for instance, about the quantitative effects of fiscal or monetary policy changes.

Calibration procedures provide a clear-cut separation between the information used to parameterize the model and the quantitative question that is being addressed by the theory. For instance, inference about the sources of business cycle fluctuations is not based on information about the cyclical properties of macroeconomic time series, such as output and hours worked, unless the theory has deemed this variability to be exogenous. While this approach may provide clear and understandable answers, they are only as good as the information that has been used to restrict and parameterize the models (and this information is rarely discussed). The fact that the calibration approach ignores salient features of the economic time series that it wants to understand is often seen as a serious shortcoming by its critics. Its advocates, on the other hand, emphasize that most of our models are not designed to capture all the dynamics that we observe in macroeconomic aggregates and that ignoring (some of) them makes the quantitative analysis more robust to model misspecification.

A starting point for the use of formal econometric methods is the observation that DSGE models deliver a complete multivariate stochastic process representation for the data they aim to explain and hence a likelihood function. This likelihood function can in principle be used to efficiently extract information about model parameters contained in macroeconomic time series and to generate sharp quantitative results. Unlike in the calibration approach, inference about the sources of business cycle fluctuations will be based on all the available 
information about the cyclical variability of macroeconomic time series. To the extent that a theoretical DSGE model is not designed to capture all of the observed dynamics because it omits some important alternative sources of business cycle fluctuations or the internal propagation of exogenous shocks is very stylized, one would need to remove effects of nonmodelled shocks from the data and/or enlarge the theoretical model through the inclusion of additional shocks and frictions in the propagation mechanism to improve its ability to fit actual data. For instance, both ? and Christiano, Eichenbaum, and Evans (2005) consider stochastic growth models that are enriched by various forms of adjustment costs to generate more realistic dynamics. The authors of the former paper augment their model by a large set of structural shocks to capture all comovements of seven macroeconomic variables, whereas the latter paper essentially uses a structural vector autoregression (VAR) to remove all variation from the data except for the fluctuations generated by monetary policy shocks.

Regardless of affiliation with the calibration or estimation tribe, the following principles seem desirable to us. First, a careful empirical analysis based on a dynamic macroeconomic model should convey to the reader which model parameters are most influential in generating a quantitative answer to the substantive question addressed in the study. Second, a detailed discussion (and careful choice) of observations that are suitable to identify plausible values for the DSGE model parameters is important. Third, measures of precision and/or robustness of the quantitative findings should be reported.

Documenting key properties of the model has nothing to do with a choice between calibration and estimation. Instead parameter identification is what is crucial in this respect. While the identification of model parameters is closely linked to, say, the choice of a criterion function for an econometric estimator, we will make the case that the choice of the criterion function is context-specific and should be preceded by a careful examination of which observations could be most informative about particular parameters. Some calibrators simply take parameter values from previous studies and plug them into their model without verifying that these parameter values lead to the same observational patterns that have motivated their choice in the first place. Researchers who estimate DSGE models often ignore important observations and do examine whether it is possible to identify all model parameters based on the autocovariance properties of the limited number of time series that do enter the likelihood function. The recent surge of papers discussing and diagnosing identification problems in estimated DSGE models, e.g., Canova and Sala (2009) and Iskrev 
(2009), is a testament to this neglect. While measures of precision in calibration papers often take the form of robustness exercises that perturb key parameters, econometric studies tend to make probabilistic statements about quantitative findings.

Although our paper focuses on quantitative methodologies, a brief review of the very extensive yet non-conclusive literature on the importance of technology shocks for fluctuations of hours worked is in order. We will distinguish between papers that calibrate DSGE models, estimate DSGE models, and estimate structural VARs. A stylized version of the neoclassical growth model calibrated to U.S. data can generate around $20 \%$ of the observed variation $^{2}$ in hours worked (see Cooley and Prescott (1995)). In Hansen (1985)'s indivisible labor model the volatility of hours reaches about $66 \%$ of the actual volatility as long as households are capable of using lotteries to allocate time to market activities. Other studies allow for variations of labor on both the intensive and extensive margin, variable capital utilization, home production, imperfect competition, incomplete markets, and labor search frictions. Based on our reading of the literature, the fraction of variation of hours worked explained by technology shocks ranges from $10 \%$ to $80 \%$, with a median of about $30 \%$.

Altug (1989) estimated the Kydland and Prescott (1982) one-shock time-to-build model using maximum likelihood techniques. She introduced measurement errors to account for the fluctuations of hours worked (and other variables used in the estimation procedure) that are not driven by technology shocks and obtained that the $12 \%$ of variation in hours was due to variation in technology shocks. McGrattan (1994) estimates a stochastic growth model with distortionary labor and capital taxes and finds that $20 \%$ of the fluctuations in hours worked are due to technology shocks. Chang and Schorfheide (2003) consider a home production model, which is estimated based on data of aggregate output, hours worked, and consumption of durable goods. According to their analysis, technology shocks account for $50 \%$ of the variation in hours worked. Galí and Rabanal (2004) fit a New Keynesian DSGE model to observations on output, inflation, interest rates, and hours worked and find that technology shocks have virtually no effect on hours over the business cycle. Most recently, Justiniano, Primiceri, and Tambalotti (2009a) estimate a state-of-the-art DSGE model with nominal wage and price rigidities and find that at low frequencies, hours fluctuations are due to a fairly persistent wage mark-up shock. At business cycle frequencies, $60 \%$ and $10 \%$

\footnotetext{
${ }^{2}$ Throughout the paper, we report findings in terms of variances or ratios of variances, because unlike standard deviations variances are additive.
} 
of the variance of hours are explained by investment-specific and neutral technology shocks, respectively.

In structural VARs, technology shocks are often identified through the assumption that they are the only shocks that have a permanent effect on labor productivity. Shapiro and Watson (1988) estimate VARs using data on aggregate output, hours worked, the aggregate price level, and interest rates. They report that $32 \%(40 \%)$ of the variation in hours is due to technology shocks, assuming that hours have a stochastic trend (are trend stationary). Following the work of Greenwood, Hercowitz, and Krusell (1997), the more recent literature distinguishes between neutral and investment-specific technology shocks. Using a structural VAR, Galí and Rabanal (2004) find that neutral technology shocks explain very little of the variation in hours. Investment-specific technology shocks, on the other hand, can explain about $60 \%$. According to Fisher (2006), neutral technology shocks account for 21\% (15\%) over the period 1955:Q1-1979:Q2 (1982:Q3 to 2000:Q4), whereas investment-specific technology shocks account for up to $47 \%(36 \%)$ of the fluctuations in hours worked. Canova, Lopez-Salido, and Michelacci (2007) estimate that the contribution of the neutral technology shock to hours variation is close to zero, while the investmentspecific shock accounts for between $20 \%$ and $50 \%$ of the variance of hours.

The remainder of this paper is organized as follows. We present the model in Section 2. The empirical analysis is carried out in Sections 3 and 4. In both sections, we parameterize the DSGE model, then repeatedly simulate artificial data with the model using the two technology shocks as driving forces, and compute the average ratio of the sample variance of simulated data to the variance of postwar U.S. data. Section 3 focuses on standard calibration procedures. In particular, we discuss how different sources of information about the labor elasticity completely determine the results. Productivity shocks are important for hours worked fluctuations if the Frisch elasticity is around two or larger. Section 4 reports on the DSGE model estimation using state-of-the-art Bayesian techniques and the answer that it yields to our main question. We also provide novel insights about the identification of the labor supply elasticity in a likelihood-based approach. Roughly speaking, the DSGE model incorporates enough restrictions to identify technology shock innovations from the observables. The dynamic responses of labor productivity and hours to these innovations identify the Frisch elasticity. However, to the extent that the estimated DSGE model has difficulties reproducing the dynamic responses of a less restrictive vector autoregressive 
specification, this identification approach is on shaky grounds.

Finally, Section 5 concludes. In a nutshell, we think that the specific statistical methods that are used to relate the model to the data are not the source of disparity in the quantitative results. Instead, the disparity is caused by the identification strategy that is used to choose the key parameter, which is the labor supply elasticity in our application. The appendix provides detailed information on the data set as well as the implementation of the empirical analysis. Data and software to replicate the empirical analysis are available on the web at http://www.ssc.upenn.edu/ ${ }^{\sim}$ schorf.

\section{The Model Economy}

We consider what we think is the latest implementation of the plain-vanilla real business cycles model: a stochastic growth model with two types of technology shocks. A neutral productivity shock affects total factor productivity. The second shock is investment-specific and shifts the slope of the transformation curve between consumption and capital goods. Our model is very similar to the one used by Fisher (2006). It is a simplified version of the model studied by Greenwood, Hercowitz, and Krusell (2000) in that we only have one capital good and the degree of capital utilization is fixed.

Instead of using a more elaborate model specification as in Justiniano, Primiceri, and Tambalotti (2009a), we focus on a frictionless version of the neoclassical growth model for two reasons. First, our stylized theoretical model is likely to fit worse, in terms of being able to track and forecast the observed time series, than a more densely parameterized statistical model such as a VAR. Therefore, our illustration captures a key aspect of most empirical work with DSGE models: the theoretically coherent model is limited in its ability to fit time series data and misspecification is a concern. Second, there will only be one parameter for which identification is tenuous and that crucially affects the quantitative findings: the aggregate Frisch labor supply elasticity. This makes it easy to pinpoint how the criterion functions, used to specify parameters in each of the quantitative approaches, translate into different answers for the role of technology shocks in shaping the behavior of aggregate output and hours.

The model economy is populated with a continuum of households with the following 
preferences:

$$
\max _{\left\{C_{t}, X_{t}, H_{t}, K_{t+1}\right\}} \quad \mathbb{E}_{0}\left[\sum_{t=0}^{\infty} \beta^{t}\left(\ln C_{t}-\xi \frac{H_{t}^{1+1 / \nu}}{1+1 / \nu}\right)\right] .
$$

Here $C_{t}$ denotes consumption, and $H_{t}$ hours worked. The nice feature of these preferences is that the parameter $\nu$ is the Frisch elasticity of substitution of labor. $\beta$ is, as always, the discount rate. $\xi$ affects the marginal rate of substitution between consumption and leisure and determines steady state hours. There is a constant returns to scale production function given by

$$
C_{t}+\frac{1}{V_{t}} X_{t}=A_{t} K_{t}^{\alpha} H_{t}^{1-\alpha}
$$

The left-hand side of (2) can be interpreted as a linear transformation curve between consumption and investment goods. The slope of this curve is shifted by the investment-specific technology disturbance $V_{t}$. The right-hand side takes the standard Cobb-Douglas form, and $A_{t}$ is an exogenous total factor productivity (or neutral) technology process. In other words, technology is subject to two shocks: a standard neutral technology shock $A_{t}$ and a sectorspecific technology shock $V_{t}$. Capital depreciates geometrically at rate $\delta$, yielding

$$
K_{t+1}=(1-\delta) K_{t}+X_{t}
$$

This economy is not distorted, and the standard procedure of solving the social planner's problem in order to find the equilibrium applies. However, it is important to make a few notes in terms of National Income and Product Accounting (NIPA) that will link the model naturally with the data. NIPA measures output in terms of the consumption good. Define $I_{t}=X_{t} / V_{t}$, and hence the aggregate resource constraint can be written as

$$
Y_{t}=C_{t}+I_{t}=A_{t} K_{t}^{\alpha} H_{t}^{1-\alpha}
$$

Under competitive markets, the relative price of a unit of the investment good using the consumption good as numeraire, $P_{t}$, gives us the technology shock $1 / V_{t}$. Using the investment series and some considerations to be detailed below to get the appropriate depreciation rate, we can construct a series for capital $K_{t}$. From here, using the Cobb-Douglas assumption on production and the average labor share for the entire sample period as an estimate of $\alpha$, we can obtain the series $A_{t}$ using (2) (see, for example, Ríos-Rull and Santaeulalia (2009) for details). 
The static Euler equation defines the labor supply schedule that, after substituting the marginal productivity of labor with its associated equilibrium wage, can be expressed as

$$
H_{t}=\left(\frac{1}{\xi} \frac{W_{t}}{C_{t}}\right)^{\nu}
$$

The dynamic Euler equation, again substituting expressions for the relative price of the investment good and the interest rate, is of the form

$$
1=\beta \mathbb{E}_{t}\left[\frac{P_{t+1} / C_{t+1}}{P_{t} / C_{t}}\left((1-\delta)+R_{t+1}\right)\right]
$$

where

$$
R_{t+1} P_{t+1}=\alpha A_{t+1} K_{t+1}^{\alpha-1} H_{t+1}^{1-\alpha}
$$

At this point our model has two exogenous disturbances, namely a neutral and an investment-specific technology process. To examine the effect of technology fluctuations on hours worked, we assume that

$$
\begin{aligned}
\left(\ln A_{t}-\ln A_{0}-\gamma_{a} t\right)= & \rho_{a, 1}\left(\ln A_{t-1}-\ln A_{0}-\gamma_{a}(t-1)\right) \\
& +\rho_{a, 2}\left(\ln A_{t-2}-\ln A_{0}-\gamma_{a}(t-2)\right)+\sigma_{a} \epsilon_{a, t} \\
\left(\ln V_{t}-\ln V_{0}-\gamma_{v} t\right)= & \rho_{v, 1}\left(\ln V_{t-1}-\ln V_{0}-\gamma_{v}(t-1)\right) \\
& +\rho_{v, 2}\left(\ln V_{t-2}-\ln V_{0}-\gamma_{v}(t-2)\right)+\sigma_{v} \epsilon_{v, t} .
\end{aligned}
$$

Thus, the log technologies fluctuate around a linear deterministic trend path, given by $\ln A_{0}+\gamma_{a} t$ and $\ln V_{0}+\gamma_{v} t$, respectively. If the autoregressive coefficients sum to one, the fluctuations are non-stationary and the technology processes can be rewritten as $\operatorname{AR}(1)$ processes in terms of growth rates. The most widely used specifications for the neutral technology process can be easily obtained as special cases of (4). If $0 \leq \rho_{a, 1}<1$ and $\rho_{a, 2}=0$, then technology follows a stationary $\operatorname{AR}(1)$ process. If $\rho_{a, 1}+\rho_{a, 2}=1$, then technology has a unit root and the serial correlation of its growth rates is $-\rho_{a, 2}$, which is often assumed to be zero. In order to restrict the autoregressive processes in (4) and (5) to trend stationarity, it is convenient to re-parameterize them in terms of partial autocorrelations $\psi_{1}$ and $\psi_{2}$. Omitting the $a$ and $v$ subscripts, we let

$$
\rho_{1}=\psi_{1}\left(1-\psi_{2}\right), \quad \rho_{2}=\psi_{2} .
$$


In case of a unit root $\psi_{1}=1$. The analysis in this paper is conducted under the assumption that the two innovations $\epsilon_{a, t}$ and $\epsilon_{v, t}$ are normally distributed with mean zero and variances $\sigma_{a}^{2}$ and $\sigma_{v}^{2}$. Moreover, we assume that they are uncorrelated at all leads and lags. ${ }^{3}$

Regardless of whether the technology shocks have a stochastic trend component (unit root) or are trend stationary, the following transformations generate stationary variables:

$$
\frac{Y_{t}}{Q_{t}}, \quad \frac{C_{t}}{Q_{t}}, \quad \frac{I_{t}}{Q_{t}}, \quad \frac{X_{t}}{Q_{t} V_{t}}, \quad \frac{K_{t+1}}{Q_{t} V_{t}}, \quad \frac{W_{t}}{Q_{t}}, \quad \text { where } \quad Q_{t}=A_{t}^{\frac{1}{1-\alpha}} V_{t}^{\frac{\alpha}{1-\alpha}}
$$

To approximate the model dynamics, we rewrite the equilibrium conditions in terms of these detrended variables, derive a non-stochastic steady state, log-linearize the equilibrium conditions around the steady state, and use a standard procedure to solve the resulting linear rational expectations system. For this extremely simple economy, a log-linear approximation is typically used in the literature as it is deemed to be accurate enough.

The parameters of the model economy belong to three categories: the four that affect the steady state of the model are $\alpha, \beta, \delta$, and $\xi$ (capital share of output, discount rate, depreciation rate, and relative weight of consumption and leisure in the utility function); those that affect the law of motion of the technology disturbances which are $\ln A_{0}, \psi_{a, 1}$, $\psi_{a, 2}, \sigma_{a}, \ln V_{0}, \psi_{v, 1}, \psi_{v, 2}$, and $\sigma_{v}$; and the Frisch labor supply elasticity $\nu$, which in this particular model economy only affects non-steady state behavior (the appropriate choice of $\xi$ makes sure that this is the case), and hence the internal propagation mechanism.

We will subsequently examine the role of shifts in investment-specific technology and total factor productivity for fluctuations of hours worked. The model economy serves as a theoretical framework for the quantitative analysis and will be calibrated in Section 3 and estimated in Section 4. In particular, we use calibration and estimation techniques to determine numerical values for its parameters, simulate data from the model based on random draws of the technology processes, and compare the variance of the model-generated data to the sample variance of postwar U.S. data.

\footnotetext{
${ }^{3}$ In principle, one could model $\ln A_{t}$ and $\ln V_{t}$ as vector autoregressive processes. However, empirically it turns out that the cross-correlations are small. Since the extension to a VAR process seems neither quantitatively important nor essential to the methodological issues discussed in this paper, we decided to impose that the two technology shocks are uncorrelated.
} 


\section{Calibration}

The calibration process starts by choosing targets that are used to obtain parameter values. These targets are not supposed to involve the answer that is pursued. Consider our specific application. We measure the fraction of cyclical variation in hours that is due to technology shocks. If we would use the cyclical variability of hours as a target, we would attribute all of it to technology shocks, since these are the only shocks in the model. We would obtain an answer of $100 \%$ by construction. Thus, the calibration does not use evidence from time series movements of endogenous variables that are centrally related to the question that is addressed.

For our model economy, most, but not all, of the parameters (labor share of output $\alpha$, depreciation rate $\delta$, discount rate, $\beta$, and weight of leisure in the utility function $\xi$ ) are easily determined by choosing steady-state conditions pertaining to NIPA aggregates, rates of return, and average fraction of time allocated to market activities. We discuss how to set them in Section 3.1. Simple assumptions on competition in factor markets and the Cobb-Douglas shape of production yield a theory-consistent construction of the exogenous shock series. Our method of obtaining the parameters that control the process for the two technology shocks is described in Sections 3.2 and 3.3. Obtaining a value for the Frisch elasticity, $\nu$, is, however, less straightforward. Hence, we pursue several different strategies to determine a suitable value in Section 3.4.

Once values for all model parameters have been specified, the answer that we are searching for is the size of the fluctuations of output and hours in the model in response to technology shocks relative to the fluctuations of these variables in the data. We obtain the answer by simulating output and hours worked data from the log-linearized model economy. We then compute variance ratios for HP-filtered (with the smoothing parameter set to 1600) simulated and actual data. Unless otherwise noted, our analysis is based on data from 1955:Q3 to 2006:Q4. Our findings are reported in Section 3.5. Precise data definitions are provided in the appendix.

\subsection{Exploiting Steady-State Relationships}

According to our specification, factor markets are competitive and the aggregate production function has a Cobb-Douglas form. Hence, the implied labor share $W_{t} H_{t} / Y_{t}$ is equal to $1-\alpha$. 
While the observed labor share is time-varying (see, for instance, Ríos-Rull and Santaeulalia (2009)), it displays no clear trend. Hence, we target the steady state of the model to have the average labor share in the data, which we take to be 0.34 . We also target an investment to output ratio of $28 \%$, a yearly interest rate of $4 \%$, and a value of leisure of $2 / 3$ of total available time. These choices yield values of $\alpha=0.34, \beta=0.99$, and $\delta=0.013$ in quarterly terms. ${ }^{4}$ The value of parameter $\xi$, while necessary to set steady-state leisure to two-thirds, actually does not affect the decision rules in a log-linear approximation and is irrelevant for the behavior of the model.

\subsection{Empirical Measures of the Exogenous Disturbances}

In the model economy, the investment-specific technology shock is the relative price of investment in terms of consumption. We construct this relative price by combining a price index for quality-adjusted equipment investment with a price index for investment in structures. With regard to the equipment investment price index, ?, Greenwood, Hercowitz, and Krusell (1997), and Cummins and Violante (2002) reveal substantial evidence of biases in the trend of official price indexes due to the lack of quality adjustment. We build on the annual series of Cummins and Violante (2002) to construct our quarterly series of quality-adjusted equipment investment. Quarterly movements are imputed based on the official index reported by the Bureau of Economic Analysis (BEA) in the Fixed Asset Tables (FAT-BEA). As a price index for investment in structures we use the consumption deflator, $P_{t}^{C}$. The two indixes are combined with a Tornquist aggregator to obtain a quality-adjusted price index for total investment, $P_{t}^{I}$. We then define

$$
P_{t}=P_{t}^{I} / P_{t}^{C} \quad \text { and } \quad V_{t}=1 / P_{t}
$$

normalizing the index such that $P_{0}=1$ in 1947 .

The series for the neutral technology process $A_{t}$ is typically computed using measures of per capita real output $Y_{t}$, capital $K_{t}$, labor input $H_{t}$, and an estimate of the capital input share $\alpha$ :

$$
\ln A_{t}=\ln Y_{t}-\alpha \ln K_{t}-(1-\alpha) \ln H_{t} .
$$

\footnotetext{
${ }^{4}$ The definition of labor share has many subtleties that we avoid here altogether; see the aforementioned Ríos-Rull and Santaeulalia (2009) or Cooley and Prescott (1995). The three parameter values also determined the capital-to-output ratio, which is sometimes used for calibration instead of the investment-to-output ratio. For our model specification, capital measured in consumption terms is 2.54 times yearly output.
} 
What is non-standard in our analysis is that we have to construct a quality-adjusted capital stock. To do so, we begin by generating a quarterly series for investment in efficiency units:

$$
X_{t}=\left(I_{t}^{E}+I_{t}^{S}\right) / Q_{t}^{I},
$$

where $I_{t}^{E}$ and $I_{t}^{S}$ are total nominal investment in equipment and structures, respectively, and $Q_{t}^{I}$ is the quality-adjusted price index that appears in (7). The quality-adjusted capital stock is obtained by the perpetual inventory method:

$$
K_{t+1}=(1-\delta) K_{t}+X_{t}
$$

where $\delta$ corresponds to the average of Cummins and Violante (2002)'s physical depreciation rates for total capital. The initial capital stock $K_{0}$ is calibrated using the observed level of output and the investment to output ratio in 1947.

\subsection{Parameterizing the Shock Processes}

Based on the measures of $\ln A_{t}$ and $\ln V_{t}$, it is straightforward to estimate coefficients for the autoregressive models (4) and (5). Rather than using least-squares methods, we employ Bayesian techniques to estimate the shock processes. This makes the estimates directly comparable to those reported for the full DSGE model in Section 4. Bayesian estimates are obtained by combining a prior distribution for the parameters of an econometric model, generically denoted by $\theta \in \Theta$, with a likelihood function

$$
p(\theta \mid Y)=\frac{p(Y \mid \theta) p(\theta)}{p(Y)}, \quad p(Y)=\int_{\theta \in \Theta} p(Y \mid \theta) p(\theta) d \theta .
$$

Here $p(\theta)$ denotes the prior density, $p(Y \mid \theta)$ is the likelihood function, that is, the joint probability density function of the data $Y$ given $\theta, p(\theta \mid Y)$ is the posterior density, and $p(Y)$ is the so-called marginal likelihood.

As discussed in Section 2, the $\operatorname{AR}(2)$ shock processes are parameterized in terms of partial autocorrelations $\psi_{1}$ and $\psi_{2}$; see (6). These processes are trend stationary if $-1<$ $\psi_{1}, \psi_{2}<1$ and become difference stationary if $\psi_{1}=1$. We estimate the parameters subject to $0 \leq \psi_{1}<1$ (deterministic trend) and $\psi_{1}=1$ (stochastic trend). In the former case, we assume that the first order partial autocorrelation has a Beta distribution with mean 0.95 and standard deviation of 0.2. For both the difference-stationary and trend-stationary specification it is assumed that the second-order partial autocorrelation is uniformly distributed 
on the interval $(-1,1)$. Our priors are fairly agnostic with respect to the average growth rate of the technology processes and the location parameters $\ln A_{0}$ and $\ln V_{0}$, which determine the log levels of the technology disturbances. The priors for the innovation standard deviations are centered at $1 \%$ with a large variance. A summary is provided in Table 1.

We construct a joint likelihood function for the two technology processes based on a sample that ranges from 1955:Q3 to 2006:Q4, conditioning on observations from 1954:Q3 to 1955:Q2. Posterior means and 90\% probability intervals are reported in Table 2. Both technology processes are highly persistent and the estimates of $\psi_{1}$ exceed 0.97 . The growth rates of the neutral technology process are essentially uncorrelated, that is, $\hat{\psi}_{2, a}$ is near zero, whereas growth rates of $\ln V_{t}$ are strongly serially correlated with $\hat{\psi}_{2, v} \approx 0.8$. It is interesting to note that the deterministic component of technology growth is solely due to $\ln V_{t}$, which implies that it is embodied in the physical capital stock.

In a Bayesian framework, one can assign probabilities to competing model specifications and update these probabilities in light of the data. We are considering a deterministic and a stochastic trend specification for the technology shock processes, say $\mathcal{M}_{0}$ and $\mathcal{M}_{1}$. According to Bayes Theorem, the prior odds in favor of the stochastic trend specification, $\pi\left(\mathcal{M}_{1}\right) / \pi\left(\mathcal{M}_{0}\right)$, are updated via marginal likelihood ratios (so-called Bayes factors) to obtain posterior odds: ${ }^{5}$

$$
\frac{\pi\left(\mathcal{M}_{1} \mid Y\right)}{\pi\left(\mathcal{M}_{0} \mid Y\right)}=\frac{\pi\left(\mathcal{M}_{1}\right)}{\pi\left(\mathcal{M}_{0}\right)} \times \frac{p\left(Y \mid \mathcal{M}_{1}\right)}{p\left(Y \mid \mathcal{M}_{0}\right)} .
$$

We report log marginal likelihood values for our two specifications (see (9) for a definition) in the last row of Table 2. The Bayes factor in favor of the stochastic trend version is approximately $e^{20}$, indicating that it is preferable to impose the unit roots.

\subsection{Calibrating the Labor Supply Elasticity}

At this point, we have chosen numerical values for all model parameters except the Frisch labor supply elasticity $\nu$. Given our specification of preferences, the steady state does not depend on this parameter. A variety of approaches have been pursued in the literature to parameterize $\nu$, which we describe in turn.

\footnotetext{
${ }^{5}$ Marginal likelihood values can be interpreted as a measure of in-sample fit that is adjusted by a penalty for model complexity.
} 
Calibration through long-run growth properties. A reasonable description of the last 100 years of Western experience is the statement that while there has been a massive increase of wages, by an order of magnitude if not more, interest rates and the allocation of hours per capita have not displayed any such long-run trend. Most preference structures are not consistent with this pattern. The most widely used preferences in business cycles research that are consistent with this long-term behavior belong to the Cobb-Douglas family, $\frac{\left(c^{\gamma} \ell^{1-\gamma}\right)^{1-\sigma}}{1-\sigma}$, where $\ell=1-H$ is leisure and the endowment of time is normalized to one. The Frisch elasticity of this specification is given by $\nu=\frac{1-H_{*}}{H_{*}}$, where $H_{*}$ is the steady-state value of hours worked. Clearly, with these preferences the Frisch elasticity is determined not from short-run variation in hours worked but from the choice of steady-state hours and indirectly through the lack of variation in the long run. ${ }^{6}$ If the average hours worked per adult per week is set to one third, ${ }^{7}$ which is a standard choice, the implied elasticity is 2 . A choice of 25 hours per week that weighs young people and retirees more heavily yields an elasticity of 3 .

Non-convexities and lotteries. Most of the variation in hours over the business cycle occurs along the extensive margin (number of workers rather than hours per worker). To account for such variation, Rogerson (1988) developed a model where agents care about leisure but face a non-convexity in the opportunities to work. These agents can use a lottery arrangement to maximize the utility ex ante. Ex post some will work and the others will not. After aggregation, this arrangement yields quasi-linear preferences for a representative consumer and the economy-wide elasticity of substitution can be infinite, regardless of the individual value of the Frisch elasticity. To see this, assume now that $h \in\{0, \bar{h}\}$, and that the agent chooses a probability of working $p$, solving

$$
\max _{c, p} \ln c-p \bar{\xi} \bar{h}^{1+1 / \nu}
$$

\footnotetext{
${ }^{6}$ Other types of preferences used in the literature that are consistent with a balanced growth path are those posed by King, Plosser, and Rebelo (1988). With these preferences, the steady-state level of hours also determines the Frisch elasticity of substitution. Herrendorf and Ríos-Rull (2009) argue that balanced growth paths do not impose any real restrictions on business cycle models.

${ }^{7}$ The U.S. Bureau of Labor Statistics reports (http://www.bls.gov/opub/working/page17b.htm) 67 hours per week worked by a married couple between the ages of 25 and 54. Conventionally, we think of 100 hours per week per person as the available discretionary time.
} 
subject to $h \in\{0, \bar{h}\}$ and $c=w p \bar{h}+a$, for some wealth $a$. In this context, the aggregate amount of hours is just $H=p \bar{h}$ and the intratemporal first-order condition implies $w / c=$ $\overline{\xi h}^{1 / \nu}$. Thus, we can replace the individual agents by a representative household that chooses $C$ and $H$ to maximize $\ln C-\xi H$ subject to $C=w H+a$, where $\xi=\overline{\xi h}^{1 / \nu}$. Note that the utility function of this representative household is obtained from (1) by setting $\nu=\infty$. Hansen (1985) used these lottery arrangements as the source of his calibration strategy in a seminal paper and not surprisingly found that hours move a lot in response to productivity shocks. ${ }^{8}$ We will use a Frisch elasticity value of 100 to implement these ideas while avoiding numerical instability.

\section{Calibration from outside the model: Direct estimates of the elasticity of labor} supply from micro-level studies. There is a large literature that provides estimates of the Frisch elasticity based on micro-level studies. ${ }^{9}$ These estimates are typically very small. In his survey paper, Pencavel (1986) reports that most estimates for men are between 0 and 0.45 , with 0.2 being a typical point estimate. The labor supply elasticity is typically measured based on information about the intensive margin of prime age white males, who are full-time workers in most periods. However, it is well documented that a large fraction of hours fluctuations is accounted for by movements in and out of employment (see, for instance, Kydland and Prescott (1991) who describe the extensive margin as responsible for two-thirds of the variation), and that those that have the most hours variation along the cycle are not prime age males (see Kydland (1984), Ríos-Rull (1993), and Kydland and Prescott (1993)). In addition, Domeij and Floden (2006) argue that, due to borrowing constraints, the estimates may be biased downward up to 50\%. Imai and Keane (2004) estimate the elasticity explicitly accounting for human capital accumulation and obtain a value as high as 3.82. With human capital accumulation of the learning by doing variety, the macro models would need to be adjusted as in Chang, Gomes, and Schorfheide (2002). More recently, Heathcote, Storesletten, and Violante (2007) estimate a value for the household elasticity of 0.72 using a definition of the household that includes both a husband and

\footnotetext{
${ }^{8}$ Kydland and Prescott (1991) built a model with both intensive and extensive margin with the use of lotteries and calibrated it using both balanced growth path restrictions and the relative volatility of hours and bodies. Unfortunately, this strategy found few followers.

${ }^{9}$ Becker and Ghez (1975), MaCurdy (1981), Altonji (1986), and Abowd and Card (1989), to name a few classic papers.
} 
a wife, while Heathcote, Storesletten, and Violante (2008) obtain 0.38 when taking into account household heterogeneity and measurement error but without using the notion of a multi-person household. To encompass the wide range of micro-level estimates, we report the behavior of an economy with Frisch elasticities of $0.2,0.38$, and 0.72 , respectively.

To summarize, the calibration strategy involved in setting the Frisch elasticity of labor supply does not have a unique or an uncontroversial target to be satisfied by an infinitely lived, representative agent model. Consequently, we will consider five values for the labor supply elasticity in the remainder of this section. First, $\nu=2$ represents a value that is chosen based on strong functional form assumptions and balanced growth path considerations. Second, we consider $\nu=100$, which essentially captures the quasi-linear preferences in Hansen (1985)'s indivisible labor model. Finally, $\nu=0.2$ represents micro-level estimates based on labor adjustments of males along the intensive margin, while $\nu=0.38$ and, especially, $\nu=0.72$ are micro-level estimates that take to heart some of the criticisms of macroeconomists (Rogerson and Wallenius (2007), for instance) about what is the object of interest when measuring the aggregate labor supply elasticity.

\subsection{Quantitative Results}

We are now in a position to examine the answers obtained from the different calibration strategies. The main findings are reported in Table 3. The top panel of the table contains results for the trend stationary parameterization of the shock processes given in the left half of Table 2, whereas the bottom panel summarizes results under the assumption that the shocks are difference stationary with parameters given in the right half of that table. Conditional on the two parameter settings, we simulate the linearized DSGE model for 310 periods using only the neutral technology process (A), only the investment-specific technology process $(\mathrm{V})$, and both technology disturbances $(\mathrm{A}+\mathrm{V})$. We discard the first 100 observations and calculate the variances of HP-filtered output and hours based on the remaining 210 observations. These variances are then divided by the variances of HPfiltered postwar U.S. aggregate output and hours worked. The simulation steps are repeated 1,000 times, and the entries in Table 3 correspond to means and standard deviations of the variance ratios across the 1,000 simulations.

The variance ratios for hours worked lie between 0.01 to 1.50 , an enormous range that encompasses all possible answers. The differences arise not from the shock processes but 
from the choice of substitution elasticity. An elasticity based on the logic that preferences have to be consistent with balanced growth yields an answer of $0.32^{10}(0.29$ for the stochastic trend specification). Assuming the existence of complete markets and indivisibilities results in hours moving (much) more in the model than in the data. An elasticity based on males responses mostly along the intensive margin yields essentially no contribution of productivity shocks to movements in hours. If we take the Frisch elasticities estimated by Heathcote, Storesletten, and Violante (2008) in their clever use of closed form solutions when taking into account household heterogeneity and measurement error (0.38), and by Heathcote, Storesletten, and Violante (2007) (0.72) using the total household hours variation specification, the answers that we obtain are 0.03 and 0.09 , respectively (0.02 and 0.07 if we impose unit roots).

The answers that one obtains are somewhat sensitive to the choice of shock process (deterministic versus stochastic trend). The contribution of technology shocks is larger for the deterministic trend than for the unit root specification. However, more striking is the enormous sensitivity to the Frisch elasticity, which generates variations in the results by more than two orders of magnitude. Interestingly, the investment-specific technical change is the main culprit of hours variation with over $80 \%$ of the total variation in all model economies. Output variation, on the other hand, is mostly driven by the neutral technology process. ${ }^{11}$ The variance ratios for output range from $20 \%$ to $80 \%$. Output variation is directly affected by the neutral technology shock and indirectly through the fluctuation of hours and capital over the business cycle.

\section{Bayesian Estimation of the DSGE Model}

We now turn to the search for the answer of how important are productivity shocks for movements in hours when using formal econometric methods. We use Bayesian estimation

\footnotetext{
${ }^{10}$ This is the same answer obtained by Kydland and Prescott (1991). They reported a ratio of standard deviations of about two-thirds, which corresponds with around 0.44 in terms of variances.

${ }^{11}$ One should not compare the contribution of the neutral shock with the total factor productivity (TFP) shock in most of the literature because they are computed very differently. In fact, the procedure that we followed in this paper reduces the role of the neutral technology shock because we increase the size of the stock of capital.
} 
techniques, ${ }^{12}$ partly as a result of personal tastes and expertise and partly because they reflect state-of-the-art econometrics and are by now widely used in practice. First, we choose the observables and the model specifications to be estimated. Second, we describe how we elicit priors for DSGE model parameters and for Frisch elasticity of labor supply, and then discuss posterior estimates. Third, we present variance ratios for hours worked computed from HP-filtered simulated and actual data for all model specification and data set combinations. Finally, we discuss the identification of labor supply elasticity and shed light on why our estimation yields a fairly low estimate of it.

\subsection{Data and Estimated Specifications}

A crucial step in the estimation is the choice of observables $Y$ that enter the likelihood function $p(Y \mid \theta)$. Since the goal is to determine the contribution of productivity shocks to the variation of hours, these series should be ingredients for our estimation. Following the tradition in econometrics, we use labor productivity instead of total factor productivity, because the construction of the latter would require the knowledge of parameters that we are trying to estimate. Fortunately, according to our theory the investment-specific technology shock is under perfect competition exactly the relative price of consumption versus investment. This gives us the three main series to use in the estimation: labor productivity $Y / H$, hours worked $H$, and relative price of investment goods $P$.

With three series and two shocks, one encounters a well-known singularity problem. According to the model, there exists a linear combination of the three series that can be predicted without error conditional on past observations. To overcome the singularity, researchers either introduce measurement errors, e.g., Altug (1989), or include additional shocks, e.g., Leeper and Sims (1994). In our case, as we want to measure the contribution of productivity shocks, we have to give the model economy a solid additional mechanism to also move hours. This makes it more attractive to add structural shocks and not just measurement errors. Given the findings of, among many others, Hall (1997) and Chari, Kehoe, and McGrattan (2007), a natural additional shock is a preference shock that affects the choice of hours worked. Consider the following variation of the utility function $U_{t}=$

\footnotetext{
${ }^{12} \mathrm{~A}$ detailed review of the Bayesian estimation of DSGE models can be found in An and Schorfheide (2007).
} 
$\ln C_{t}-B_{t} \xi \frac{H_{t}^{1+1 / \nu}}{1+1 / \nu}$, where $\ln B_{t}=\rho_{b} \ln B_{t-1}-\left(\sigma_{b} / \nu\right) \epsilon_{b, t}$ is such a preference shock. This will be our baseline specification.

We will also consider two additional specifications for the sake of completeness. First, instead of a preference shock, one can introduce a demand shock, such as a government spending shock, which changes the aggregate resource constraint to $Y_{t}=C_{t}+I_{t}+G_{t}$. We assume that government expenditures are financed by lump-sum taxes and are determined as a time-varying fraction of total output, $G_{t}=\left(1-1 / g_{t}\right) Y_{t}$. The process for government expenditures is exogenous and evolves according to $\ln \left(g_{t} / g^{*}\right)=\rho_{g} \ln \left(g_{t-1} / g^{*}\right)+\sigma_{g} \epsilon_{g, t} \cdot{ }^{13}$ Second, we consider a version of our model in which the preference shock and the government expenditure shock are simultaneously active. Consequently, we denote the resulting model specifications by $\{A, V, B\},\{A, V, G\}$, and $\{A, V, B, G\} .14$

Since the accumulation of the quality-adjusted investment series provides a measure of the capital stock, which in combination with aggregate output and hours worked identifies the neutral technology shock via the production function (see Section 3.2), we consider $\ln X_{t}$ as a fourth observable. We estimate the model specifications based on three samples: $\{Y / H, H, P\},\{Y / H, H, X\}$, and $\{Y / H, H, P, X\}$, with the qualification that only the fourshock model is estimated based on the four-variable sample.

\subsection{From Priors to Posteriors}

Priors. The prior distributions for the coefficients of the two technology processes are identical to those used in Section 3.3 and summarized in Table 1. As before, we will estimate versions of the DSGE model specifications in which technology shocks are stationary and versions in which we impose unit-root restrictions. The prior densities for the remaining DSGE model parameters are provided in Table 4. When we estimated only the shock processes, we introduced the location parameters $\ln A_{0}$ and $\ln V_{0}$. For the estimation of the full DSGE model based on time series of the log levels of output, hours, and the relative price of investment, we parameterize the DSGE model in terms of $\ln Y_{0}$, which

\footnotetext{
${ }^{13}$ This specification leads to the relationship $\ln Y_{t}=\ln \left(C_{t}+I_{t}\right)+\ln g_{t}$ and implies that the government share of output is stationary.

${ }^{14}$ Modern variations on this model, containing additional frictions such as sticky prices and wages (and choices of households outside their labor supply function), monopolistic competition, monetary distortions and the like, allow for many more shocks. See, for example, Smets and Wouters (2007).
} 
replaces $\ln A_{0}$, as well as $\ln V_{0}$ and the steady-state level of hours $\ln H_{*}$, which replaces $\xi$. This re-parameterization simplifies prior elicitation because in principle it allows us to use pre-sample observations. However, as before, we use fairly uninformative priors for these location parameters.

The elicitation of the prior distributions for $\alpha, \beta$, and $\delta$ follows the same steps as the calibration in Section 3.1. Note that this elicitation is based on observables that are not included in the likelihood function, such as real interest rates, the labor share, and the size of the capital stock. We use degenerate priors for two of the parameters: discount factor and depreciation rate are fixed at $\beta=0.99$ and $\delta=0.013$. Based on the labor share data, we choose a prior for $\alpha$ that is centered at 0.34 with a standard deviation of 0.02 . The prior distribution for the autocorrelation of the preference shock is centered at 0.8 and has a standard deviation of 0.1 . The corresponding values for the government spending shock process are 0.95 and 0.1 . We set $g^{*}=1.2$ if the government spending shock is included in the model and equal to one otherwise.

Our prior for the Frisch labor supply elasticity is centered at the balanced growth path value of $\nu=2$, but with a standard deviation of one. Hence, a $90 \%$ a priori credible interval encompasses values found in studies that use micro-level data for employed males, as well as the values necessary to be able to explain most of the observed volatility in hours worked in a stochastic growth model driven by technology shocks. We will also briefly discuss how our results change if we center the prior for $\nu$ at 0.72 instead of 2 , which is the value obtained from Heathcote, Storesletten, and Violante (2007)'s analysis of micro-level data.

Sample period and estimation. All versions of the DSGE model are estimated based on observations from 1955:Q3 to 2006:Q4, conditioning on observations from 1954:Q3 to 1955:Q2. This conditioning will allow a comparison of marginal likelihoods between the DSGE model specifications and a VAR. We use the Markov-Chain Monte-Carlo methods reviewed in An and Schorfheide (2007) to obtain draws from the posterior distribution of the DSGE model parameters. Detailed estimation results are provided in Table A-1 in the appendix. As long as the relative price of investment is included as an observable in the estimation, the estimates of the technology shock parameters are very similar to those reported in Table 2. If the DSGE model is estimated on the $Y / H, H, X$ data set, then $\hat{\psi}_{2, v}$ is close to zero, meaning that the growth rates of the investment-specific technology process are 
approximately serially uncorrelated. In part due to the fairly tight prior on $\alpha$, the posterior mean estimates fall in the range of 0.32 to 0.39 . Thus, the specific statistical methods used here did not change the estimates of these parameters. The coefficient estimates for the preference and government spending shocks are such that the model is able to capture the variation in output and hours worked that is not explained by the two technology shocks. We will now turn to the estimates of the Frisch elasticity, which is the parameter that really matters, as it determines the answer to our quantitative question.

Estimates of the Frisch elasticity. Table 5 reports $90 \%$ posterior credible intervals for the labor supply elasticity. If the observables consist of productivity, hours worked, and the relative price of investment, the credible intervals span the range 0.05 to 1.1 and are somewhat larger if the shocks are assumed to be trend stationary, yet highly persistent. If the price of investment is replaced by the quantity, the estimates of $\nu$ tend to increase, in particular if the government spending shock is included as shock in the model. Finally, if the four-shock model specification is estimated based on four series, the labor supply elasticity estimate drops to the range of 0.03 to 0.27 . To summarize, if we use three shocks, the elasticity estimates are in the range of those recently estimated by Heathcote, Storesletten, and Violante $(2007,2008)$ that are the modern version of studies that use micro data, while the use of four shocks reduces the estimate to values obtained using only the variation of the intensive margin of males.

\subsection{Quantitative Results}

So far, the econometric analysis has generated multiple sets of parameter estimates, which in turn will lead to a multitude of answers for our quantitative question. However, not all model specifications fit the time series data equally well, and one can use a measure of time series fit to assign more weight to parameter estimates and predictions obtained from model specifications that attain a better fit. Formally, as in Section 3.3, we use log marginal likelihoods to update prior model probabilities.

For each of the three data sets, Table 6 reports log marginal likelihood differentials (or log Bayes factors), using the specification with the highest marginal likelihood as a benchmark. For the $Y / H, H, P$ data set it appears to be slightly preferable to impose unit roots in the two technology processes and to augment the DSGE model with a government 
expenditure shock. Based on $Y / H, H, X$ observations, the trend-stationary specifications are preferred in the three-shock models. However, the best fit is obtained by the four-shock version with unit root technology processes. However, the log marginal likelihood differentials are overall fairly small, indicating that the data can only imperfectly discriminate among the various specifications.

Given a set of prior probabilities for the various DSGE model specifications, the log marginal likelihoods can be transformed into posterior probabilities, using a generalization of (10). ${ }^{15}$ Table 7 reports the posterior probabilities that are calculated under the assumption that for each data set, all DSGE model specifications have equal prior probability. Cells for model specifications with essentially zero posterior probability are left blank. While these posterior probabilities are not suitable for comparisons of estimates (and their quantitative implications) across data sets, they do provide coherent model specification weights conditional on a particular data set.

For each model specification and data set combination, Table 8 reports means and standard deviations of variance ratios computed from HP-filtered simulated and actual data. All entries refer to the combined effect of neutral and investment-specific technology shocks on output and hours worked, and the boldfaced entries indicate posterior probabilities higher than $5 \%$. The variance ratio results mimic the labor supply elasticity estimates: high elasticities yield large effects. The largest effect of technology shocks on hours worked fluctuations is obtained from the $A, V, G$ specification estimated based on $Y / H, H, X$ data, explaining about $20 \%$ of the observed variation. Weighted by posterior model probabilities, we conclude from the $Y / H, H, X$ data that $6 \%$ of hours fluctuations (and $26 \%$ of output fluctuations) are generated by technology shocks. The corresponding numbers for the $Y / H$, $H, P$ data set are $2 \%$ and $21 \%$, respectively. Due to the small value of the estimated labor supply elasticity based on the $Y / H, H, P, X$ data set, hours essentially do not move in response to technology shocks and they explain about $21 \%$ of output fluctuations. Comparing the standard deviations in Tables 3 and 8, it is apparent that accounting for parameter uncertainty increases the variability of the variance ratios substantially. We re-estimated some of the models with a prior for $\nu$ centered at 0.72 . This lowers the posterior estimates of $\nu$ and slightly reduces the importance of the technology shocks for hours fluctuations.

\footnotetext{
${ }^{15}$ Consider a collection of models $\mathcal{M}_{m}, m=1, \ldots, M$. The posterior probability of $\mathcal{M}_{m}$ is $\pi\left(\mathcal{M}_{m} \mid Y\right)=$ $\pi\left(\mathcal{M}_{m}\right) p\left(Y \mid \mathcal{M}_{m}\right) / p(Y)$, where $p(Y)=\sum_{m=1}^{M} \pi\left(\mathcal{M}_{m}\right) p\left(Y \mid \mathcal{M}_{m}\right)$ and $\pi\left(\mathcal{M}_{m}\right)$ is the prior probability of $\mathcal{M}_{m}$.
} 
A recent literature uses an expanded version of the neoclassical growth model, includes various nominal and real frictions as well as several additional shocks, and provides an answer to the same question that we pursue. Justiniano, Primiceri, and Tambalotti (2009a) estimate one of these expanded models with the same Bayesian techniques used in this paper. They assess the contribution of technology shocks (especially investment-specific shocks) to be up to $60 \%$ of hours variation at business cycle frequencies. The reasons for this discrepancy with our findings include the fact that in their environment with fixed wages, a fraction of agents is unable to re-optimize their price and forced to supply whatever number of hours is demanded at the posted price; thus, even with small Frisch elasticity, hours tend to move a lot in response to technology shocks. Another source of discrepancy, at least compared to our estimation with the $Y / H, H, P$ and $Y / H, H, P, X$ data sets, is the fact that they treat the investment shock as a latent process, which turns out to be much more volatile than the relative price of investment. Justiniano, Primiceri, and Tambalotti (2009b) include the relative price of investment as an observable but allow for an additional (unobserved) shock, to the marginal efficiency of installed investment. They find that this shock plays a big role in accounting for hours variation relative to the observed shocks to the relative price of investment. Liu, Waggoner, and Zha (2009) impute most of the role in shaping fluctuations (especially when focusing on the Great Moderation) on the role of neutral technological shocks, capital depreciation shocks, and wage mark-up shocks, while they argue that investment-specific technology shocks played a small role.

Overall, the econometrics procedure points to a relatively low labor supply elasticity, especially if we let two additional shocks (government expenditure and preference shocks), on top of the productivity shocks, move hours. There is, however, one important caveat. In Table 6 we also report log marginal likelihoods for a VAR with four lags under a Minnesota prior. For all three data sets, the VAR attains a better time series fit than the DSGE model specification as indicated by the positive marginal likelihood difference in excess of 30 relative to the preferred DSGE model version. The superior fit of the VARs is evidence for DSGE model misspecification in the sense that some of the theory implied cross-equation restrictions are at odds with the data. We now look in more detail at how these procedures identify the elasticity, and the extent to which such identification results are convincing. 


\subsection{Identification of the Labor Supply Elasticity}

The likelihood-based estimator, at the heart of econometrics, delivers a parameter value for which the model implied autocovariance function of the observables matches the sample autocovariance function as closely as possible in terms of a statistical metric. It does so by forcing each shock in the model to contribute particular autocovariance features, which in total have to mimic the sample autocovariances. This matching is, unfortunately, often difficult to interpret because there is no transparent link from patterns in the data to particular parameter estimates. The goal of this section is to shed some light on why our likelihood-based estimation yields a fairly low estimate of the labor supply elasticity.

In a traditional simultaneous equations model that characterizes demand and supply in a market, the identification condition for the supply elasticity is the availability of an observable exogenous variable that only shifts the demand curve. One can then measure the simultaneous change in prices and quantities in response to a change in the demand shifter, which in turn identifies the supply elasticity. Identification in a DSGE model is more complicated for two reasons. First, unobserved structural shocks rather than directly observed exogenous variables play the role of demand and supply shifters. Second, any given structural shock is likely to shift both the demand and the supply function simultaneously. A neutral technology shock, for example, tends to increase labor demand because the marginal product of labor increases. At the same time, this rise in income generated by higher productivity might induce the household to reduce its labor supply. Thus, if one has direct observations on an exogenous shock and the supply and demand curves shift simultaneously, the challenge is to disentangle the slopes of both curves. If the exogenous shock is a latent variable, then the identification of the labor supply elasticity becomes even more tenuous because the mapping from the observables into the latent shock might depend on it.

According to our simple DSGE model, data on the relative price of investment can serve as direct observations for the investment-specific technology shock. Thus, the $\{m Y / H, H, P\}$ and $\{Y / H, H, P, X\}$ data sets include direct observations of a shock that shifts the labor market equilibrium. Moreover, data on output, hours worked, and quality-adjusted investment implicitly generate an observation of the neutral technology shock as follows. According to the capital accumulation equation:

$$
K_{t+1}=\sum_{j=0}^{t-1}(1-\delta)^{j} X_{t}+(1-\delta)^{t-1} K_{1}, \quad t>1 .
$$


Since $\delta>0$ for $t$ sufficiently large, the capital stock is well approximated by a weighted average of past investment. As in the calibration analysis, the neutral technology shock can be recovered from the production function

$$
A_{t}=\frac{Y_{t}}{K_{t}^{\alpha} H_{t}^{1-\alpha}}
$$

Notice that the construction of $A_{t}$ does not depend on the value of the labor supply elasticity $\nu$ and recall that $\alpha$ can be identified from labor share observations, which entered our analysis indirectly through the prior distribution.

The assumption that the technology shocks are exogenous generates exclusion restrictions that are sufficient to identify dynamic responses of labor market variables to innovations in $\epsilon_{v, t}\left(\epsilon_{a, t}\right)$ in the $\{Y / H, H, P\}\{Y / H, H, X\}$ and $\{Y / H, H, P, X\}$ data sets. Since the two technology shocks enter the model in an identical manner, without loss of generality we will focus on the response to an investment-specific technology shock. Along the response to a technology shock, the labor supply condition, here written in terms of temporal differences $\Delta$, has to be satisfied:

$$
\Delta \hat{h}_{t}=\nu\left(\Delta \hat{w}_{t}-\Delta \hat{c}_{t}\right)
$$

Here $\hat{h}_{t}$ denotes hours in percentage deviations from its steady state, and $\hat{w}_{t}$ and $\hat{c}_{t}$ denote percentage deviations of detrended real wages and consumption from their respective steady states. Since consumption is not included in the list of observables used in our likelihoodbased estimation, we will replace it by a function of wages, hours, and technology shock. Assuming that $\psi_{1, v}=1$, that is, the investment-specific technology process is difference stationary, we show in the appendix that in response to a one standard deviation investmentspecific technology shock in period $t=1$ the wage and hours dynamics for $t>1$ can be expressed as:

$$
\Delta \hat{h}_{t}=\nu\left[\Delta \hat{w}_{t}+r^{*}\left(1-\alpha^{-1}\right) \hat{w}_{t}-\left(-\psi_{2, v}\right)^{t-1} \frac{\sigma_{v}}{1-\alpha}\right]
$$

where $r^{*}=R^{*} /\left(R^{*}+1-\delta\right)$, and $R^{*}=e^{\left(\gamma_{a}+\gamma_{v}\right) /(1-\alpha)} / \beta-(1-\delta)$. Recall that $r^{*}$ and $\alpha$ are identifiable from long-run averages of the labor share, real interest rates, and the investment-capital ratio, which enter our estimation objective function implicitly through the prior distribution. Thus, information on the impulse responses of wages (which are equal to average labor productivity in our Cobb-Douglas environment with constant factor shares) and hours worked to an investment-specific technology shock, which is encoded in the likelihood function, suffices to identify the labor supply elasticity. 
Broadly speaking, technology shocks for which we can implicitly construct observations independently of the labor supply elasticity play the same role as exogenous demand shifters (or instrumental variables) in the analysis of traditional simultaneous equations systems: they perturb the market equilibrium and move prices and quantities. However, in DSGE models these technology shocks tend to shift both supply and demand. Since the slope of the labor demand function is through functional form assumptions essentially identified from the average labor share, observing the movements of wages and hours in response to the perturbation is sufficient for the determination of the labor supply elasticity.

Thus far, we have established that the labor supply elasticity is identifiable based on the information (both prior and sample) that we are using in the estimation. We will focus on the $\{Y / H, H, P\}$ data set and the $\{A, V, B\}$ DSGE model specification in which technology shocks are difference stationary and the third shock is a preference shock. Using actual and simulated data we estimate a structural VAR(4) in labor productivity growth, hours worked, and investment-specific technology growth, imposing the following identification restrictions: two of the three shocks driving $\{Y / H, H, P\}$ are technology shocks. The investment-specific technology growth (inflation in the relative price of investment) is exogenous and follows an AR(1) process. The non-technology shock does not shift the labor demand schedule upon impact because capital is fixed in the short-run. These restrictions are also hardwired into our DSGE model.

Based on the $Y / H, H, P$ data set, we construct posterior estimates of the DSGE model parameters subject to the restrictions that the two technology shocks have a stochastic trend and that the Frisch elasticity is equal to either 0.2 or 2.0. We then use these estimates to generate two time series of 2,000 observations, one based on a model with a low Frisch elasticity and one based on a large Frisch elasticity. The resulting VAR-based impulse response estimates are depicted in Figure 1. While the response estimates of productivity and hours to a neutral technology (A) shock and a non-technology (B) shock obtained from actual and simulated data more or less match, there is a significant difference across samples between the estimated response of productivity and hours to an investment-specific technology (V) shock. For instance, based on actual data the productivity response to the investment shock is negative, whereas it is (slightly) positive for simulated data. Thus, in view of this impulse response mismatch, the DSGE model appears to be misspecified or the investment shock to be mismeasured, which is consistent with the evidence from the log 
marginal likelihoods reported in Table 6 .

The hours responses provide conflicting information about the labor supply elasticity. To match the responses to an investment shock and the non-technology shock, the labor supply elasticity should be small; that is, a value of 0.2 is preferred over a value of 2 . To reproduce the empirical response to a neutral technology shock, on the other hand, a large Frisch elasticity is needed. The estimate of $\nu$ is ultimately determined by the implicit weighting of the discrepancy between sample and DSGE model implied autocovariance functions (and hence VAR-based impulse response function estimates) encoded in the likelihood function. It turned out to be low, which suggests that the B- and V-shock responses received relatively more weight than the A-shock response.

To the extent that the relative price of investment potentially provides only a noisy measure of investment-specific technology and overstates the serial correlation of technology growth rates or the propagation of the investment shock is incorrectly modelled, heavily relying on the hours response to an innovation in the price of investment goods for the identification of a key parameter may be undesirable. Rather than using the implicit weighting of the likelihood function, one could construct an alternative estimator of $\nu$ based on weighting schemes that place more weight on, say, the response to a neutral technology shock. ${ }^{16}$ This estimator of $\nu$ would be larger than the estimates reported in Table 5. Ultimately, such a procedure is likely to reproduce the same answer to the question of the importance of technology shocks, which is obtained from a structural VAR. This VAR uses only a minimal subset of restrictions implied by our theoretical model, just sufficient to identify innovations to structural shocks.

\section{Conclusion}

The analysis in the previous sections suggests that the differences in the answers provided by the various quantitative methods are not due to the statistical apparatus but instead due to the source of identification of key parameters, a fundamental economic issue. In a perfect world, different sources would yield mutually consistent conclusions after the precision of the information has been properly accounted for. Unfortunately, that is not the

\footnotetext{
${ }^{16}$ Christiano, Eichenbaum, and Evans (2005) follow this path when estimating a monetary DSGE model by matching responses to a monetary policy shock.
} 
case if one works with fairly stylized and to some extent misspecified models, as we do in quantitative macroeconomics. The reality is that different identification approaches often yield conflicting results.

Our application illustrated that among calibrated models, the answers differ dramatically depending on the source of information about the Frisch elasticity. While it is easy to doubt the two extreme values (which are based on middle-aged full-time working white men, the most irrelevant group from a business cycle point of view or in never seen lotteries), the value of 2 is also not free from strong criticism. It is based on the logic of balanced growth paths, which has come under attack recently (Herrendorf and Ríos-Rull (2009)). After all, it is hard to see what insights long-term trends generate for business cycle issues. The use of micro based estimates that take into account both the work of men and women and the intensive and extensive margins as in Heathcote, Storesletten, and Violante (2007, 2008) deliver arguably the most plausible estimates of $\nu$ and imply that between $3 \%$ to $9 \%$ of hours fluctuations are explained by technology shocks.

Understanding the source of parameter identification in the context of likelihood-based estimation is difficult and has been neglected in the recent literature on DSGE model estimation. We made some progress in the context of our fairly stylized stochastic growth model by characterizing the model-implied restrictions that identify structural shocks and comparing VAR impulse response functions estimated based on actual and simulated data. While this analysis is useful for understanding whether parameters are identifiable, it is difficult to disentangle what drives a particular estimate, once it becomes apparent that there are patterns in the data that the model is unable to reproduce. Moreover, this approach is potentially sensitive to mismeasurements of shock innovations as well as misspecification of the propagation mechanisms, such as omissions of short-term adjustment mechanisms that generate hump-shaped instead of monotonic responses. Nonetheless, based on our Bayesian estimation, we find that across different model specifications about $6 \%$ of the variation of hours is due to technology shocks, though some specifications yield estimates as high as $20 \%$. It is interesting to note that despite very different sources of identification, our preferred calibration and the Bayesian estimation yield similar answers, conditional on a common theoretical framework.

The exercises conducted in this paper have convinced us that, regardless of our preferences for quantitative methodologies, we should place more emphasis on searching for 
reliable sources of identification of key parameters and making these sources transparent to our audience.

\section{References}

Abowd, J. M., And D. CARD (1989): "On the Covariance Structure of Earnings and Hours Changes," 57(2), 411-445.

AltonjI, J. (1986): "Intertemporal Substitution in Labor Supply: Evidence from Micro Data," Journal of Political Economy, 94, s176-s215.

Altug, S. (1989): "Time-to-Build and Aggregate Fluctuations: Some New Evidence," International Economic Review, 30(4), 889-920.

An, S., And F. Schorfheide (2007): "Bayesian Analysis of DSGE Models," Econometric Reviews, 26((2-4)), 113-172.

Becker, G. S., and G. Ghez (1975): The Allocation of Time and Goods Over the Life Cycle. New York: Columbia University Press.

Canova, F., D. Lopez-Salido, and C. Michelacci (2007): "On the Effects of Technology Shocks on Hours and Output: A Robustness Analysis," mimeo, CEMFI and UPF, CEPR DP 6720.

Canova, F., And L. Sala (2009): "Back to Square One: Identification Issues in DSGE Models," 56(4), 431-449.

Chang, Y., J. F. Gomes, and F. Schorfheide (2002): "Learning-by-Doing as a Propagation Mechanism," American Economic Review, 92(5), 1498-1520.

Chang, Y., and F. Schorfheide (2003): "Labor-Supply Shifts and Economic Fluctuations," Journal of Monetary Economics, 50(8), 1751-1768.

Chari, V. V., P. J. Kehoe, and E. R. McGrattan (2007): "Business Cycle Accounting," 75((3)), 781-836.

Christiano, L., M. Eichenbaum, and C. Evans (2005): "Nominal Rigidities and the Dynamic Effects of a Shock to Monetary Policy," Journal of Political Economy, 113(1), $1-45$. 
Cooley, T. F., and E. C. Prescott (1995): "Economic Growth and Business Cycles," in Frontiers of Business Cycle Research, ed. by T. F. Cooley, chap. 1. Princeton NJ: Princeton University Press.

Cummins, J. G., and G. L. Violante (2002): "Investment-Specific Technical Change in the United States (1947-2000): Measurement and Macroeconomic Consequences," Review of Economic Dynamics, 5((2),).

DomeiJ, D., And M. Floden (2006): "The Labor-Supply Elasticity and Borrowing Constraints: Why Estimates are Biased," 9(2), 242-262.

Fisher, J. D. (2006): "The Dynamic Effects of Neutral and Investment-Specific Technology Shocks," Journal of Political Economy, 114(3), 413-451.

Galí, J., And P. Rabanal (2004): "Technology Shocks and Aggregate Fluctuations: How Well Does the Real Business Cycle Model Fit Postwar US Data?," IMF Working Paper $\mathrm{WP} / 04 / 234$.

Greenwood, J., Z. Hercowitz, and P. Krusell (1997): "Long-Run Implications of Investment-Specific Technological Change," 87(3), 342-362.

Greenwood, J., Z. Hercowitz, and P. Krusell (2000): "The Role of InvestmentSpecific Technological Change in the Business Cycle," European Economic Review, $44((1)), 91-115$.

Hall, R. E. (1997): "Macroeconomic Fluctuations and the Allocation of Time," Journal of Labor Economics, 15(1), S223-250.

Hansen, G. D. (1985): "Indivisible Labor and the Business Cycle," 16((3)), 309-321.

Heathcote, J., K. Storesletten, and G. Violante (2007): "Consumption and Labor Supply with Partial Insurance: An Analytical Framework," University of Oslo, Frisch Centre (Oslo) Working Paper.

(2008): “The Macroeconomic Implications of Rising Wage Inequality in the United States," University of Oslo, Frisch Centre (Oslo) Working Paper.

Herrendorf, B., And J. V. Ríos-Rull (2009): "Balanced Growth Paths and Preferences: There Is No Need for CRRA Felicity Functions," Unpublished manuscript, University of Minnesota. 
Imai, S., And M. P. Keane (2004): "Intertemporal Labor Supply and Human Capital Accumulation," International Economic Review, 45(2), 601-641.

Iskrev, N. (2009): "Local Identification in DSGE Models," Estudos e Documentos de Trabalho, Banco de Portugal.

Justiniano, A., G. E. Primiceri, and A. Tambalotti (2009a): "Investment Shocks and Business Cycles,” http://faculty.wcas.northwestern.edu/〜gep575/samm40_gt.pdf.

- (2009b): "Investment Shocks and the Relative Price of Investment," http://faculty.wcas.northwestern.edu/〜 gep575/ISRP7_gt.pdf.

King, R. G., C. I. Plosser, and S. Rebelo (1988): "Production, Growth and Business Cycles: I The Basic Neoclassical Model," 21(2-3), 195-232.

Kydland, F. E. (1984): "Labor-Force Heterogeneity and the Business Cycle," 21, 173-209.

Kydland, F. E., and E. C. Prescott (1982): "Time to Build and Aggregate Fluctuations," 50(6), 1345-1370.

_ (1991): "Hours and Employment Variation in Business Cycle Theory," 1(1), 63-81.

— (1993): "Cyclical Movements of the Labor Input and Its Implicit Real Wage," Federal Reserve Bank of Cleveland Economic Review, QII, 12-23.

Leeper, E. M., And C. A. Sims (1994): "Toward a Modern Macroeconomic Model Usable for Policy Analysis," in NBER MAcroeconomics Annual 1994, ed. by S. Fischer, and J. J. Rotemberg, vol. 9, pp. 81-140. Cambridge, MA: MIT Press.

Liu, Z., D. F. Waggoner, And T. Zha (2009): "Sources of the Great Moderation: Shocks, Frictions, or Monetary Policy?," Working Paper 2009-03, Federal Reserve Bank of Atlanta.

MaCurdy, T. E. (1981): "An Empirical Model of Labor Supply in a Life-Cycle Setting," 89, 1059-1085.

McGrattan, E. R. (1994): "The Macroeconomic Effects of Distortionary Taxation," Journal of Monetary Economics, 33(3), 573-601. 
Pencavel, J. (1986): "Labor Supply of Men: A Survey," in Handbook of Labor Economics, ed. by O. Ashenfelter, and R. Layard, vol. 1. Amsterdam: Elsevier Science Publishers.

Ríos-Rull, J.-V. (1993): "Working in the Market, Working at Home, and the Acquisition of Skills: A General-Equilibrium Approach," 83(4), 893-907.

RÍos-Rull, J.-V., and R. Santaeulalia (2009): "Productivity Shocks and Redustributive Shocks," Mimeo, CAERP, and Washington University in St. Louis.

Rogerson, R. (1988): "Indivisible Labor Lotteries and Equilibrium," 21, 3-16.

Rogerson, R., And J. Wallenius (2007): "Micro and Macro Elasticities in a Life Cycle Model with Taxes," NBER WP 13017.

Shapiro, M. D., and M. W. Watson (1988): "Sources of Business Cycle Fluctuations," $3,111-156$.

Smets, F., And R. Wouters (2007): "Shocks and Frictions in US Business Cycles: A Bayesian DSGE Approach," American Economic Review, 97(3), 586-606. 
Table 1: Prior Distribution for Technology Shock Parameters for the CaliBRATION VERSION

\begin{tabular}{lclcc}
\hline \hline Name & Domain & Density & Para (1) & Para (2) \\
\hline$\gamma_{a}$ & $\mathbb{R}$ & Normal & 0.00 & 0.10 \\
$\psi_{1, a}$ & $\mathbb{R}^{+}$ & Beta & 0.95 & 0.02 \\
$\psi_{2, a}$ & $(-1,1)$ & Uniform & -1.0 & 1.00 \\
$\sigma_{a}$ & $\mathbb{R}^{+}$ & InvGamma & 0.01 & 4.00 \\
\hline$\gamma_{v}$ & $\mathbb{R}$ & Normal & 0.00 & 0.10 \\
$\psi_{1, v}$ & $\mathbb{R}{ }^{+}$ & Beta & 0.95 & 0.02 \\
$\psi_{2, v}$ & $(-1,1)$ & Uniform & -1.0 & 1.00 \\
$\sigma_{v}$ & $\mathbb{R}{ }^{+}$ & InvGamma & 0.01 & 4.00 \\
\hline $\ln A_{0}$ & $\mathbb{R}$ & Normal & 0.00 & 100 \\
$\ln V_{0}$ & $\mathbb{R}$ & Normal & 0.00 & 100 \\
\hline
\end{tabular}

Notes: Para (1) and Para (2) list the means and the standard deviations for Beta, Gamma, and Normal distributions; the upper and lower bound of the support for the Uniform distribution; $s$ and $\nu$ for the Inverse Gamma distribution, where $p_{\mathcal{I G}}(\sigma \mid \nu, s) \propto \sigma^{-\nu-1} e^{-\nu s^{2} / 2 \sigma^{2}}$. To estimate the stochastic growth version of the model, we set $\psi_{1, a}=\psi_{1, v}=1$. 
Table 2: Posterior Distribution for Technology Shock Parameters for the Calibration Version

\begin{tabular}{lcccc}
\hline \hline & \multicolumn{2}{c}{ Deterministic Trend } & \multicolumn{2}{c}{ Stochastic Trend } \\
Name & Mean & $90 \%$ Intv. & Mean & $90 \%$ Intv. \\
\hline$\gamma_{a}$ & -0.001 & {$[-0.002,0.000]$} & 0.000 & {$[-0.001,0.001]$} \\
$\psi_{1, a}$ & 0.974 & {$[0.962,0.987]$} & 1.000 & \\
$\psi_{2, a}$ & -0.027 & {$[-0.152,0.094]$} & -0.060 & {$[-0.185,0.050]$} \\
$\sigma_{a}$ & 0.007 & {$[0.006,0.008]$} & 0.007 & {$[0.006,0.008]$} \\
\hline$\gamma_{v}$ & 0.008 & {$[0.007,0.008]$} & 0.007 & {$[0.005,0.009]$} \\
$\psi_{1, v}$ & 0.994 & {$[0.991,0.997]$} & 1.000 & \\
$\psi_{2, v}$ & -0.762 & {$[-0.835,-0.688]$} & -0.808 & {$[-0.899,-0.726]$} \\
$\sigma_{v}$ & 0.003 & {$[0.003,0.004]$} & 0.003 & {$[0.003,0.004]$} \\
\hline $\ln A_{0}$ & 4.838 & {$[4.744,4.948]$} & -2.661 & {$[-97.404,76.500]$} \\
$\ln V_{0}$ & -0.144 & {$[-0.239,-0.058]$} & -0.846 & {$[-79.870,86.089]$} \\
\hline $\ln p(Y)$ & & 1585.56 & & 1604.90 \\
\hline
\end{tabular}




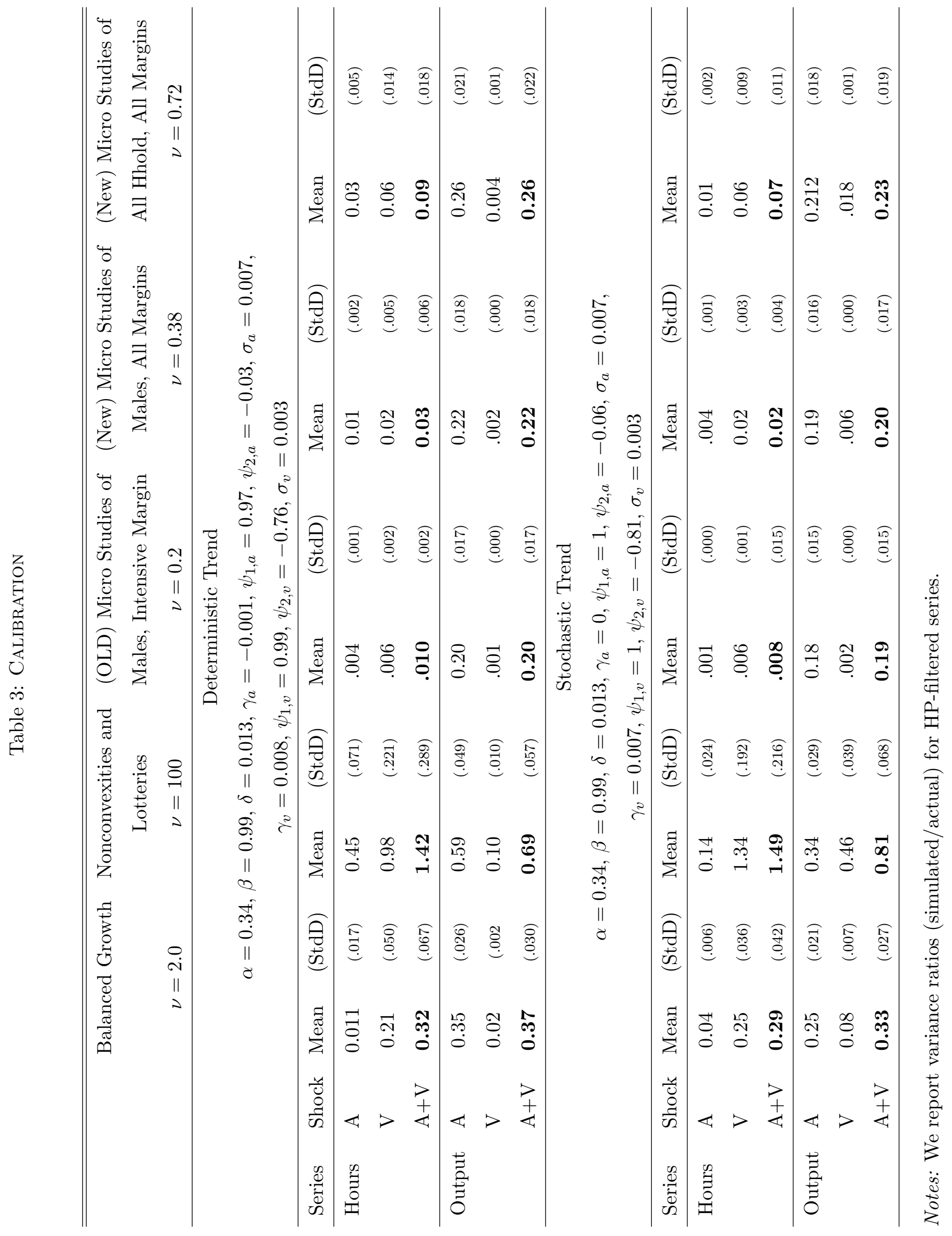


Table 4: Prior Distribution for DSGE Model Parameters

\begin{tabular}{lclcc}
\hline \hline Name & Domain & Density & Para (1) & Para (2) \\
\hline$\alpha$ & {$[0,1)$} & Beta & 0.34 & 0.02 \\
$\beta$ & & fixed & 0.99 & \\
$\delta$ & & fixed & .013 & \\
$\nu$ & $\mathbb{R}^{+}$ & Gamma & 2.00 & 1.00 \\
\hline$\rho_{b}$ & $\mathbb{R}^{+}$ & Beta & 0.80 & 0.1 \\
$\sigma_{b}$ & $\mathbb{R}^{+}$ & InvGamma & 0.01 & 4.00 \\
$g^{*}$ & & fixed & 1.00 or 1.20 \\
$\rho_{g}$ & $\mathbb{R}^{+}$ & Beta & 0.95 & 0.02 \\
$\sigma_{g}$ & $\mathbb{R}^{+}$ & InvGamma & 0.01 & 4.00 \\
\hline $\ln H_{*}$ & $\mathbb{R}$ & Normal & 0.00 & 10.0 \\
$\ln Y_{0}$ & $\mathbb{R}$ & Normal & 0.00 & 100 \\
\hline & & & &
\end{tabular}

Notes: Para (1) and Para (2) list the means and the standard deviations for Beta, Gamma, and Normal distributions; the upper and lower bound of the support for the Uniform distribution; $s$ and $\nu$ for the Inverse Gamma distribution, where $p_{\mathcal{I G}}(\sigma \mid \nu, s) \propto \sigma^{-\nu-1} e^{-\nu s^{2} / 2 \sigma^{2}}$. To estimate the stochastic growth version of the model, we set $\psi_{1, a}=\psi_{1, v}=1$. 
Table 5: Labor Supply Elasticity Estimates

\begin{tabular}{|c|c|c|c|c|}
\hline \multicolumn{2}{|c|}{ Unit Roots } & \multicolumn{3}{|c|}{ Data Set } \\
\hline Imposed & Shocks & $\mathrm{Y} / \mathrm{H}, \mathrm{H}, \mathrm{P}$ & $\mathrm{Y} / \mathrm{H}, \mathrm{H}, \mathrm{X}$ & $\mathrm{Y} / \mathrm{H}, \mathrm{H}, \mathrm{P}, \mathrm{X}$ \\
\hline \multicolumn{5}{|c|}{ Labor Supply Elasticities, $90 \%$ Intv. } \\
\hline \multirow[t]{3}{*}{ No } & $\mathrm{A}, \mathrm{V}, \mathrm{B}$ & {$[0.27,1.09]$} & {$[0.38,1.10]$} & \\
\hline & $\mathrm{A}, \mathrm{V}, \mathrm{G}$ & {$[0.35,0.89]$} & {$[0.93,2.17]$} & \\
\hline & $\mathrm{A}, \mathrm{V}, \mathrm{B}, \mathrm{G}$ & {$[0.34,1.01]$} & {$[0.33,1.30]$} & {$[0.05,0.27]$} \\
\hline \multirow[t]{3}{*}{ Yes } & $\mathrm{A}, \mathrm{V}, \mathrm{B}$ & {$[0.05,0.40]$} & {$[0.24,0.82]$} & \\
\hline & $\mathrm{A}, \mathrm{V}, \mathrm{G}$ & {$[0.17,0.64]$} & {$[1.05,2.60]$} & \\
\hline & $\mathrm{A}, \mathrm{V}, \mathrm{B}, \mathrm{G}$ & {$[0.12,0.66]$} & {$[0.27,2.28]$} & {$[0.03,0.20]$} \\
\hline
\end{tabular}


Table 6: Log Marginal Likelihoods

\begin{tabular}{llccc}
\hline \hline $\begin{array}{l}\text { Unit Roots } \\
\text { Imposed }\end{array}$ & Shocks & Y/H, H, P & Y/H, H, X & Y/H, H, P, X \\
\hline \multicolumn{4}{c}{ Log Marginal Likelihood Differentials } \\
\hline No & A, V, B & -13.58 & -0.46 \\
& A, V, G & -3.38 & -7.10 \\
& A, V, B, G & -6.94 & -5.49 & 0.00 \\
\hline Yes & A, V, B & -9.04 & -3.52 & \\
& A, V, G & 0.00 & -9.52 & \\
\hline VAR(4), Minnesota Prior & 54.72 & 34.46 & 57.30 \\
\hline
\end{tabular}

Notes: For each data set, the log marginal likelihood differences are computed relative to the DSGE model specification with the highest marginal likelihood. The log marginal likelihoods for these specifications are 2278.12, 1945.58, and 2820.11, respectively.

Table 7: Posterior Probabilities

\begin{tabular}{|c|c|c|c|c|}
\hline \multicolumn{2}{|c|}{ Unit Roots } & \multicolumn{3}{|c|}{ Data Set } \\
\hline Imposed & Shocks & $\mathrm{Y} / \mathrm{H}, \mathrm{H}, \mathrm{P}$ & $\mathrm{Y} / \mathrm{H}, \mathrm{H}, \mathrm{X}$ & $\mathrm{Y} / \mathrm{H}, \mathrm{H}, \mathrm{P}, \mathrm{X}$ \\
\hline \multicolumn{5}{|c|}{ Posterior Probabilities } \\
\hline \multirow[t]{3}{*}{ No } & $\mathrm{A}, \mathrm{V}, \mathrm{B}$ & & 0.38 & \\
\hline & $\mathrm{A}, \mathrm{V}, \mathrm{G}$ & 0.03 & & \\
\hline & $\mathrm{A}, \mathrm{V}, \mathrm{B}, \mathrm{G}$ & & & 1.00 \\
\hline \multirow[t]{3}{*}{ Yes } & $\mathrm{A}, \mathrm{V}, \mathrm{B}$ & & 0.02 & \\
\hline & $\mathrm{A}, \mathrm{V}, \mathrm{G}$ & 0.96 & & \\
\hline & $\mathrm{A}, \mathrm{V}, \mathrm{B}, \mathrm{G}$ & & 0.60 & \\
\hline
\end{tabular}


Table 8: Importance of TeChnology Shocks

\begin{tabular}{|c|c|c|c|c|c|}
\hline \multicolumn{3}{|c|}{ Unit Roots } & \multicolumn{3}{|c|}{ Data Set } \\
\hline Imposed & Shocks & Series & $\mathrm{Y} / \mathrm{H}, \mathrm{H}, \mathrm{P}$ & $\mathrm{Y} / \mathrm{H}, \mathrm{H}, \mathrm{X}$ & $\mathrm{Y} / \mathrm{H}, \mathrm{H}, \mathrm{P}, \mathrm{X}$ \\
\hline \multirow[t]{6}{*}{ No } & $\mathrm{A}, \mathrm{V}, \mathrm{B}$ & Hours & $0.08(.054)$ & $\mathbf{0 . 0 5}(.024$ & \\
\hline & & Output & $0.25(.038)$ & $\mathbf{0 . 2 5}(.038)$ & \\
\hline & $\mathrm{A}, \mathrm{V}, \mathrm{G}$ & Hours & $\mathbf{0 . 0 8}(.046)$ & $0.22(.084)$ & \\
\hline & & Output & $\mathbf{0 . 2 5}(.037)$ & $0.33(.047)$ & \\
\hline & $\mathrm{A}, \mathrm{V}, \mathrm{B}, \mathrm{G}$ & Hours & $0.10(.055)$ & $0.09(.058)$ & $.009(.008)$ \\
\hline & & Output & $0.25(.039)$ & $0.28(.046)$ & $\mathbf{0 . 2 1}(.031)$ \\
\hline \multirow[t]{6}{*}{ Yes } & $\mathrm{A}, \mathrm{V}, \mathrm{B}$ & Hours & $0.01(.006)$ & $\mathbf{0 . 0 3}(.015)$ & \\
\hline & & Output & $0.20(.027)$ & $\mathbf{0 . 2 2}(.032)$ & \\
\hline & $\mathrm{A}, \mathrm{V}, \mathrm{G}$ & Hours & $\mathbf{0 . 0 2}(.010)$ & $0.20(.063)$ & \\
\hline & & Output & $\mathbf{0 . 2 1}(.029)$ & $0.32(.044)$ & \\
\hline & $\mathrm{A}, \mathrm{V}, \mathrm{B}, \mathrm{G}$ & Hours & $0.02(.012)$ & $\mathbf{0 . 0 7}(.052)$ & $.002(.002)$ \\
\hline & & Output & $0.21(.030)$ & $\mathbf{0 . 2 6}(.046)$ & $0.19(.026)$ \\
\hline \multirow[t]{2}{*}{ Weighted } & & Hours & 0.02 & 0.06 & .009 \\
\hline & & Output & 0.21 & 0.26 & 0.21 \\
\hline
\end{tabular}

Notes: Variance ratios from model specifications with posterior probability $\geq 2 \%$ in bold. The last two rows (Weighted) contain weighted averages based on the posterior probabilities in Table 7. 
Figure 1: VAR Responses, Actual versus Simulated Data

$V \rightarrow$ Productivity

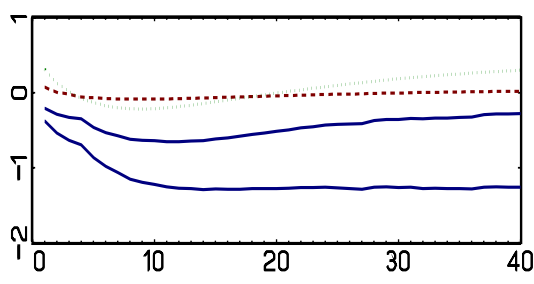

B $\rightarrow$ Productivity

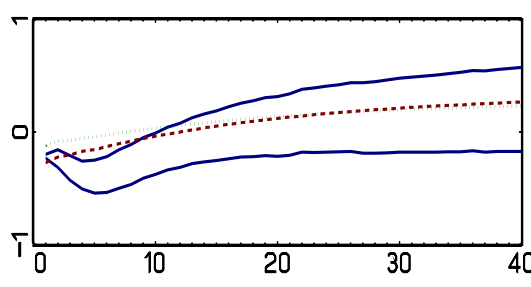

A $\rightarrow$ Productivity

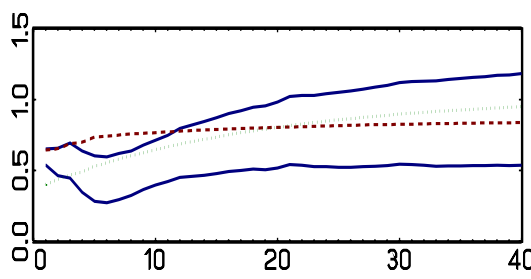

$\checkmark \rightarrow$ Hours

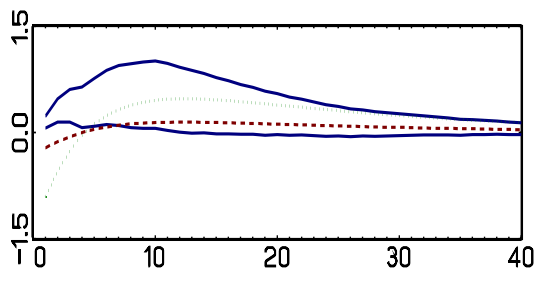

B $\rightarrow$ Hours

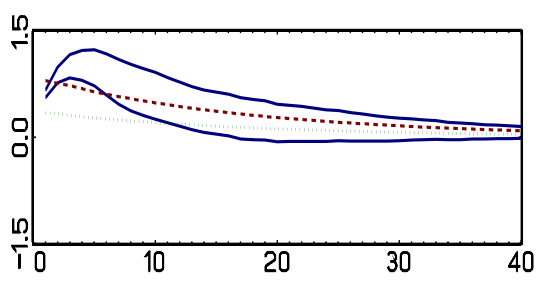

$A \rightarrow$ Hours

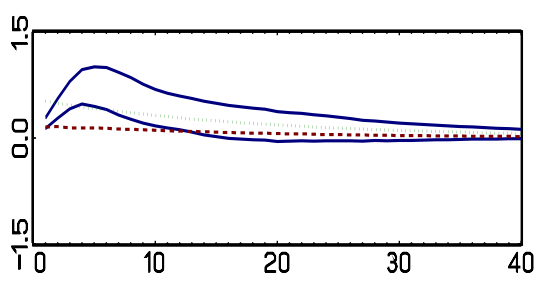

Notes: The figure depicts $90 \%$ credible bands for a VAR(4) (solid, blue) estimated based on actual data and posterior mean responses for VAR(4)'s estimated on long samples of DSGE model generated observations with $\nu=0.2$ (red, dashed) and $\nu=2.0$ (green, dashed). 


\section{A Data Construction}

\section{A.1 Raw Data Series}

All raw data series retrieved from the Bureau of Economic Analysis (BEA; www.bea.gov) and the Bureau of Labor Statistics (BLS; www.bls.gov) for the period 1948:Q1-2006:Q4 were current as of April 19, 2007.

\section{National Income and Product Accounts (NIPA-BEA)}

1. Table 1.1.5: Consumption of Durable Goods $\left(\mathrm{CD}_{t}\right)$, Change in Inventories $\left(\mathrm{ChInv}_{t}\right)$

2. Table 1.7.5: Gross National Product $\left(\mathrm{GNP}_{t}\right)$

3. Tables 2.3.3 and 2.3.5: Quantity Index $\left(\mathrm{QCONS}_{t}^{i}\right)$ and Nominal $\left(\mathrm{CONS}_{t}^{i}\right)$ Nondurables Consumption (excluding Energy) and Services (excluding Housing) ${ }^{17}$

4. Table 3.9.5: Government Investment in Equipment $\left(\right.$ GovIEQ $\left._{t}\right)$, Government Investment in Structures $\left(\right.$ GovIST $\left._{t}\right)$

5. Table 5.3.5: Private Fixed Investment in Equipment (PrivIEQ $\left.{ }_{t}\right)$, Private Fixed Investment in Structures (PriviST ${ }_{t}$ )

\section{Fixed Asset Tables (FAT-BEA)}

1. Table 5.3.4: Official Price Index for Investment in Equipment $\left(\mathrm{OPIEQ}_{t}\right)$

\section{Bureau of Labor Statistics(BLS)}

1. Aggregate Hours Index $\left(H_{t}\right)$, BLS ID PRS85006033

2. Civilian Noninstitutional Population $+16\left(P o p 16_{t}\right)$, BLS ID LNU00000000

\footnotetext{
${ }^{17}$ Goods $i$ correspond to nondurables consumption in food, clothing and shoes, and others, and services in household operations, transportation, medical care, recreation, and others.
} 


\section{Cummins and Violante (2002), 1947-2000}

1. Annual Quality-Adjusted Price Index for Investment in Equipment (QAPIEQ

2. Annual Quality-Adjusted Depreciation Rates for Total Capital $\left(\delta_{\text {year }}^{C V}\right)$

\section{A.2 The Relative Price of Quality-Adjusted Investment}

We construct the relative price of quality-adjusted investment, $P_{t}^{I}$, as a Tornquist aggregate of the price index of quality-adjusted equipment investment and the price index of structures investment. We use the price index of consumption, $P_{t}^{C}$, as a proxy for the price of structures investment. ${ }^{18}$ Based on $P_{t}^{I}$ and $P_{t}^{C}$, we define the relative price of investment goods (using the consumption good as numeraire) as

$$
P_{t}=\frac{P_{t}^{I}}{P_{t}^{C}}
$$

Its inverse, $V_{t}=\frac{1}{P_{t}}$, is investment-specific technical change. We set $V_{0}=\frac{1}{P_{0}}=1$, that is, we assume real capital is equal to capital in efficiency units in 1947.

\section{Quarterly Quality-Adjusted Price Index for Investment in Equipment, QAPIEQ .}

We use the U.S. 1947-2000 annual series provided by Cummins and Violante (2002) for the price index of equipment investment, $\mathrm{QAPIEQ}_{\text {year }}^{C V}$, and impute the quarterly movements of the official FAT-BEA price index of equipment investment, OPIEQ , $_{t}$ using the Denton

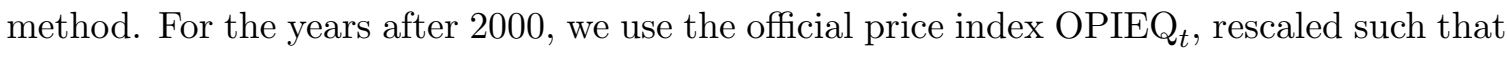
it equates the value in Cummins and Violante (2002) in the year 2000. Thus, we consider that the hedonic methods used to compute the official price index correctly quality-adjust most of types equipment investment after 2000.

Quarterly Quality-Adjusted Price Index for Total Investment, $P_{t}^{I}$. We use a Tornquist price index aggregate that weights growth rates of the price index of investment in equipment and the price index of investment in structures by their nominal shares

\footnotetext{
${ }^{18} \mathrm{As}$ is the standard in previous literature, we use the consumption deflator as the price index for investment in structures (see Fisher (2006) and Canova, Lopez-Salido, and Michelacci (2007)). This provides internal consistency in the way we compute the quality-adjusted price index for total (equipment + investment) investment - one of the elements of output is investment, hence, the alternative use of an output (instead of a consumption) deflator potentially distorts the very same measure we are trying to compute, an investment deflator.
} 
$s_{t}^{I E Q}$ and $s_{t}^{I S T}$. Nominal equipment investment is the sum of private equipment investment $\left(\right.$ PrivIEQ $\left._{t}\right)$, government equipment investment $\left(\right.$ GovIEQ $\left._{t}\right)$, changes in inventories $\left(\mathrm{ChInv}_{t}\right)$, and consumer durables $\left(\mathrm{CD}_{t}\right)$. Nominal structures investment is the sum of private structures investment $\left(\right.$ PrivIST $\left._{t}\right)$ and government structures investment $\left(\right.$ GovIST $\left._{t}\right)$. The growth rate of the quarterly quality-adjusted price index for total investment is

$$
\lambda\left(P_{t}^{I}\right)=\left(\frac{s_{t}^{I E Q}+s_{t-1}^{I E Q}}{2}\right) \lambda\left(\mathrm{QAPIEQ}_{t}\right)+\left(\frac{s_{t}^{I S T}+s_{t-1}^{I S T}}{2}\right) \lambda\left(P_{t}^{C}\right),
$$

where $\lambda\left(x_{t}\right)=\left(x_{t}-x_{t-1}\right) / x_{t}$ and changes in the price index for consumption goods, $\lambda\left(P_{t}^{C}\right)$, serve as proxy for inflation in the price of structures. The level of quarterly quality-adjusted price index for total investment is recovered recursively,

$$
P_{t}^{I}=P_{t-1}^{I}\left[1+\lambda\left(P_{t}^{I}\right)\right]
$$

We use the initial value $P_{0}^{I}$ suggested in Cummins and Violante (2002).

Quarterly Price Index for Consumption, $P_{t}^{C}$. We use a Tornquist price index aggregate that weights growth rates of price indexes for nondurables consumption (food, clothing and shoes, and others) and services (household operations, transportation, medical care, recreation, and others) by their nominal shares. Let $P_{t}^{C, i}$ be the price index for nondurable consumption/service good $i$ in quarter $t$ computed as the ratio between nominal consumption of good $i, \mathrm{CONS}_{t}^{i}$, and the quantity index of good $i, \mathrm{QCONS}_{t}^{i}$. Let $s_{t}^{i}$ be the corresponding nominal share of good $i$ in period $t$. Then, the growth rate of the price index for consumption is

$$
\lambda\left(P_{t}^{C}\right)=\sum_{i} \frac{s_{t}^{i}+s_{t-1}^{i}}{2} \lambda\left(P_{t}^{C, i}\right),
$$

The level of the consumption price index is recovered recursively,

$$
P_{t}^{C}=P_{t-1}^{C}\left[1+\lambda\left(P_{t}^{C}\right)\right]
$$

where we set $P_{0}^{C}$ such that the initial relative price of investment is equal to one; see below.

\section{A.3 Neutral Technical Change}

The series of neutral technical change is computed using measures of real output $Y_{t}$, real capital $K_{t}$, and labor input $H_{t}$, together with an estimate of the input shares of production. Real output $Y_{t}$ is computed as the nominal gross national product, $\mathrm{GNP}_{t}$, deflated by $P_{t}$. We 
convert output, capital, and hours in per capita terms dividing by civilian noninstitutional population Pop $16_{t}$. We explicitly consider capital quality improvement represented by the historical fall in the real price of investment. To do so, we build quarterly series for investment in efficiency units and physical depreciation rates that we use to construct series of quality-adjusted capital stock. Quality adjustments substantially change the series of capital - real capital falls below capital in efficiency units and affects the trend of neutral technical change.

Quarterly Quality-Adjusted Investment, $X_{t}$. Total investment in efficiency units is defined as total deannualized nominal investment deflated by the quality-adjusted price of investment,

$$
X_{t}=\frac{\operatorname{InvEQ}_{t}+\operatorname{InvST}_{t}}{P_{t}^{I}}
$$

Quarterly Quality-Adjusted Depreciation Rates, $\delta_{t}$. We build on the time-varying annual physical depreciation rates for total capital provided in Cummins and Violante (2002) for the period 1947-2000, $\delta_{\text {year }}^{C V}$. For the years after 2000, we assume a constant depreciation rate equal to that in year 2000. We define $\delta$ as the average quarterly depreciation rate over the period 1955:Q3 to 2006:Q4: $\delta=0.013$.

Quarterly Quality-Adjusted Capital Stock, $K_{t}$. We have created quarterly qualityadjusted investment series, $X_{t}$, and quarterly series for the quality-adjusted depreciation rate, $\delta_{t}$. Then we can construct the series of capital in efficiency units recursively using the perpetual inventory method,

$$
K_{t+1}=(1-\delta) K_{t}+X_{t}
$$

where the initial capital stock in efficiency units, $K_{0}$, is calibrated using the steady-state investment equation

$$
\frac{K_{0}}{Y_{0}}=\frac{V_{0} I_{0}}{Y_{0}}\left(1-(1-\delta) \exp \left(-\lambda_{K}\right)\right)^{-1}
$$

We obtain the unconditional mean of the investment-output ratio is 0.284 , and the quarterly capital per capita growth rate averages $1.08 \%$. This yields an initial quarterly capital-output ratio of 11.6 (or 2.92 annually), which together with the initial value of real output pins down an initial efficient capital stock.

Neutral Technical Change, $A_{t}$. The series of neutral technical change is computed as

$$
A_{t}=\frac{Y_{t}}{K_{t}^{\alpha} H_{t}^{1-\alpha}}
$$


where $\alpha=\sum_{t} \frac{\alpha_{t}}{T}$ is the average capital share augmented to incorporate capital income from government capital and durables.

\section{B The Model}

In terms of the transformed variables, the deterministic steady state of our model is characterized by the following set of equations:

$$
\begin{aligned}
q^{*} & =e^{\frac{1}{1-\alpha} \gamma_{a}+\frac{\alpha}{1-\alpha} \gamma_{v}} \\
v^{*} & =e^{\gamma_{v}} \\
R^{*} & =\frac{q^{*} v^{*}}{\beta}-(1-\delta) \\
\frac{K^{*}}{Y^{*}} & =\frac{\alpha q^{*} v^{*}}{R^{*}} \\
\frac{X^{*}}{Y^{*}} & =\left(1-\frac{1-\delta}{q^{*} v^{*}}\right) \frac{K^{*}}{Y^{*}} \\
\frac{I^{*}}{I^{*}} & =X^{*} \\
K^{*} & =\frac{1-\delta}{q^{*} v^{*}} \\
\frac{C^{*}}{Y^{*}} & =\frac{1}{g_{*}}-\frac{I^{*}}{Y^{*}}
\end{aligned}
$$

For the technology shock processes, let $\hat{A}_{t}=\ln A_{t}-\ln A_{0}-\gamma_{a} t$ and $\hat{V}_{t}=\ln V_{t}-\ln V_{0}-\gamma_{v} t$. For other variables $X_{t}$, let $\hat{x}_{t}=\ln \left(X_{t} / X^{*}\right)$. Then the log-linearized equilibrium conditions are given by (we scale the labor supply shock $\ln B_{t}$ by the factor $-\nu$ such that $\hat{b}_{t}=-\nu \ln B_{t}$ ):

$$
\begin{aligned}
\hat{r}_{t} & =\hat{y}_{t}-\hat{k}_{t}+\frac{1}{1-\alpha}\left(\hat{a}_{t}+\hat{v}_{t}\right) \\
\hat{w}_{t} & =\hat{y}_{t}-\hat{h}_{t} \\
\hat{c}_{t} & =E_{t}\left[\hat{c}_{t+1}\right]-\frac{R^{*}}{R^{*}+1-\delta} E_{t}\left[\hat{r}_{t+1}\right]+\frac{1}{1-\alpha} E_{t}\left[\hat{a}_{t+1}+\hat{v}_{t+1}\right] \\
\hat{h}_{t} & =\nu\left(\hat{w}_{t}-\hat{c}_{t}\right)+\hat{b}_{t} \\
\hat{y}_{t} & =g_{*} \frac{C^{*}}{Y^{*}} \hat{c}_{t}+g_{*} \frac{I^{*}}{Y^{*}} \hat{i}_{t}+\hat{g}_{t} \\
\hat{y}_{t} & =(1-\alpha) \hat{h}_{t}+\alpha \hat{k}_{t}-\frac{\alpha}{1-\alpha}\left(\hat{a}_{t}+\hat{v}_{t}\right) \\
\hat{k}_{t+1} & =\left(1-\frac{I^{*}}{K^{*}}\right) \hat{k}_{t}+\frac{I^{*}}{K^{*}} \hat{i}_{t}-\frac{1-I^{*} / K^{*}}{1-\alpha}\left(\hat{a}_{t}+\hat{v}_{t}\right)
\end{aligned}
$$


and the exogenous shock processes evolve according to

$$
\begin{aligned}
& \hat{a}_{t}=\hat{A}_{t}-\hat{A}_{t-1} \\
& \hat{v}_{t}=\hat{V}_{t}-\hat{V}_{t-1} \\
& \hat{A}_{t}=\psi_{1, a}\left(1-\psi_{2, a}\right) \hat{A}_{t-1}+\psi_{2, a} \hat{A}_{t-2}+\sigma_{a} \epsilon_{a, t} \\
& \hat{V}_{t}=\psi_{1, v}\left(1-\psi_{2, v}\right) \hat{V}_{t-1}+\psi_{2, v} \hat{V}_{t-2}+\sigma_{v} \epsilon_{v, t} \\
& \hat{b}_{t}=\rho_{b} \hat{b}_{t-1}+\sigma_{b} \epsilon_{b, t} \\
& \hat{g}_{t}=\rho_{g} \hat{g}_{t-1}+\sigma_{g} \epsilon_{g, t}
\end{aligned}
$$

For the likelihood-based estimation of the technology shock processes and the complete DSGE models we use the Kalman filter. Since $\hat{A}_{t}$ and $\hat{V}_{t}$ are potentially non-stationary, we initialize the filter by assuming that all hat-variables are equal to zero in period $t=-20$, where $t=1$ corresponds to the first observation in our sample. All likelihood function values in this paper are computed conditional on the first four sample observations $(t=1, \ldots, 4)$.

\section{Impulse Response to a Technology Shock}

We will show that the impulse response function of labor productivity and hours worked suffices to identify the labor supply elasticity. It is apparent from (A.2) that the two technology shocks enter the system in an identical manner, at least as far as detrended output, consumption, wages, hours, capital, and the rental rate of capital is concerned. Hence, without loss of generality we will focus on the response to an investment-specific technology shock. We will assume that $\psi_{1, v}=1$ and define $\tilde{v}_{t}=\hat{v}_{t} /(1-\alpha)$ and omit the hats from all other variables. Thus, the impulse response function has to satisfy the following 
equilibrium conditions:

$$
\begin{aligned}
r_{t} & =y_{t}-k_{t}+\tilde{v}_{t} \\
w_{t} & =y_{t}-h_{t} \\
c_{t} & =E_{t}\left[c_{t+1}\right]-r^{*} E_{t}\left[r_{t+1}\right]+E_{t}\left[\tilde{v}_{t+1}\right] \\
h_{t} & =\nu\left(w_{t}-c_{t}\right) \\
y_{t} & =s_{c} c_{t}+s_{i} i_{t} \\
y_{t} & =(1-\alpha) h_{t}+\alpha k_{t}-\alpha \tilde{v}_{t} \\
k_{t+1} & =\left(1-\delta^{*}\right) k_{t}+\delta^{*} i_{t}-\left(1-\delta^{*}\right) \tilde{v}_{t} \\
\tilde{v}_{t} & =-\psi_{2, v} \tilde{v}_{t-1}+\frac{\sigma_{v}}{1-\alpha} \epsilon_{v, t},
\end{aligned}
$$

where $r^{*}=R^{*} /\left(R^{*}+1-\delta\right), s_{c}=g_{*} C^{*} / Y^{*}, s_{i}=g_{*} I^{*} / Y^{*}$, and $\delta^{*}=1-(1-\delta) /\left(q^{*} v^{*}\right)$. To construct the impulse response function we assume that the system is in its steady state prior to $t=1$, that $\epsilon_{v, 1}=1$, and $\epsilon_{v, t}=0$ for $t>1$. Thus, the time-path of the technology growth process is given by

$$
\tilde{v}_{t}=\left(-\psi_{2, v}\right)^{t-1} \frac{\sigma_{v}}{1-\alpha}, \quad E_{t}\left[\tilde{v}_{t+1}\right]=\tilde{v}_{t} .
$$

After period 1 there is perfect foresight along the impulse response, and for any variable $x_{t}$ it is the case that $E_{t}\left[x_{t+1}\right]=x_{t+1}$. With this in mind, we write the system for $t>1$ as

$$
\begin{aligned}
w_{t} & =y_{t}-h_{t} \\
\Delta c_{t+1} & =r^{*}\left(y_{t+1}-k_{t+1}\right)+\left(r^{*}-1\right) \tilde{v}_{t+1} \\
h_{t} & =\nu\left(w_{t}-c_{t}\right) \\
y_{t} & =s_{c} c_{t}+s_{i} i_{t} \\
w_{t} & =\alpha\left(k_{t}-h_{t}\right)-\alpha \tilde{v}_{t} \\
k_{t+1} & =\left(1-\delta^{*}\right) k_{t}+\delta^{*} i_{t}-\left(1-\delta^{*}\right) \tilde{v}_{t}
\end{aligned}
$$

The Frisch elasticity can be obtained from the response function of wages, i.e., labor productivity, and hours worked, because it has to satisfy

$$
\Delta h_{t+1}=\nu\left(\Delta w_{t+1}+\Delta c_{t+1}\right) .
$$


While we do not use direct information on consumption in our empirical analysis, we can deduce from (A.6) that

$$
\begin{aligned}
\Delta c_{t+1} & =r^{*}\left(y_{t+1}-k_{t+1}\right)+\left(r^{*}-1\right) \tilde{v}_{t+1} \\
& =r^{*}\left(w_{t+1}-\left(k_{t+1}-h_{t+1}\right)\right)+\left(r^{*}-1\right) \tilde{v}_{t+1} \\
& =r^{*}\left(w_{t+1}-\alpha^{-1} w_{t+1}-\tilde{v}_{t+1}\right)+\left(r^{*}-1\right) \tilde{v}_{t+1} \\
& =r^{*}\left(1-\alpha^{-1}\right) w_{t+1}-\tilde{v}_{t+1} .
\end{aligned}
$$

Thus, for $t>1$ the impulse response function of wages and hours needs to satisfy

$$
\Delta h_{t+1}=\nu\left[\Delta w_{t+1}+r^{*}\left(1-\alpha^{-1}\right) w_{t+1}-\left(-\psi_{2, v}\right)^{t} \frac{\sigma_{v}}{1-\alpha}\right] .
$$

Since $r^{*}, \alpha, \psi_{2, v}$, and $\sigma_{v}$ can be identified independently from information other than that contained in the impulse response function of hours and wages to a technology shock, we deduce that $\nu$ is identifiable as long as the initial response of hours worked to a technology shock is non-zero.

\section{Further Results}

Table A-1 reports the full set of parameter estimates for the highest posterior probability specifications based on the data sets $Y / H, H, P, Y / H, H, X$, and $Y / H, H, P, X$. 
Table A-1: Posterior Estimates for Highest Post. Prob. Specifications

\begin{tabular}{lcccccc}
\hline \hline Series & & Y H, H, P & \multicolumn{2}{c}{ Y H, H, X } & \multicolumn{2}{c}{ Y H, H, P, X } \\
Shocks & & A, V, G & A, V, B, G & A, V, B, G \\
Unit Root & & Yes & & Yes & No \\
\hline$\alpha$ & 0.340 & {$[0.306,0.374]$} & 0.325 & {$[0.292,0.359]$} & 0.390 & {$[0.379,0.402]$} \\
$\nu$ & 0.419 & {$[0.168,0.643]$} & 1.235 & {$[0.273,2.276]$} & 0.162 & {$[0.049,0.271]$} \\
\hline$\gamma_{a}$ & 0.000 & {$[-0.001,0.001]$} & 0.000 & {$[-0.001,0.001]$} & -0.001 & {$[-0.001,-0.001]$} \\
$\psi_{1, a}$ & 1.000 & & 1.000 & & 0.950 & {$[0.932,0.969]$} \\
$\psi_{2, a}$ & -0.020 & {$[-0.148,0.120]$} & -0.020 & {$[-0.107,0.065]$} & -0.086 & {$[-0.200,0.030]$} \\
$\sigma_{a}$ & 0.007 & {$[0.006,0.008]$} & 0.007 & {$[0.007,0.008]$} & 0.007 & {$[0.007,0.008]$} \\
\hline$\gamma_{v}$ & 0.007 & {$[0.006,0.008]$} & 0.007 & {$[0.006,0.009]$} & 0.008 & {$[0.007,0.008]$} \\
$\psi_{1, v}$ & 1.000 & & 1.000 & & 0.991 & {$[0.988,0.994]$} \\
$\psi_{2, v}$ & -0.694 & {$[-0.769,-0.620]$} & -0.073 & {$[-0.154,0.009]$} & -0.646 & {$[-0.724,-0.570]$} \\
$\sigma_{v}$ & 0.003 & {$[0.003,0.004]$} & 0.007 & {$[0.006,0.008]$} & 0.003 & {$[0.003,0.004]$} \\
\hline$\rho_{b}$ & & & 0.950 & {$[0.910,0.989]$} & 0.946 & {$[0.925,0.968]$} \\
$\sigma_{b}$ & & & 0.010 & {$[0.007,0.013]$} & 0.009 & {$[0.008,0.010]$} \\
$\rho_{g}$ & 0.962 & {$[0.944,0.982]$} & 0.981 & {$[0.967,0.996]$} & 0.966 & {$[0.952,0.980]$} \\
$\sigma_{g}$ & 0.038 & {$[0.021,0.056]$} & 0.006 & {$[0.004,0.007]$} & 0.010 & {$[0.008,0.012]$} \\
\hline $\ln H_{*}^{*}$ & -0.028 & {$[-0.067,0.009]$} & -0.023 & {$[-0.072,0.028]$} & -0.025 & {$[-0.046,-0.005]$} \\
$\ln Y_{0}$ & -32.284 & {$[-49.319,-17.905]$} & 7.861 & {$[4.263,11.252]$} & 8.630 & {$[8.547,8.719]$} \\
$\ln V_{0}$ & 27.552 & {$[17.036,41.493]$} & 0.337 & {$[-2.131,2.887]$} & -0.149 & {$[-0.230,-0.061]$} \\
\hline
\end{tabular}

Notes: The following parameters are fixed during the estimation: $\beta=0.99, \delta=0.013$, $g^{*}=1.2$ (in models with G-shock). 